\title{
Detecting the critical periods that underpin interannual fluctuations in the carbon balance of European forests
}

\author{
Guerric le Maire, ${ }^{1,2}$ Nicolas Delpierre, ${ }^{3}$ Martin Jung, ${ }^{4}$ Philippe Ciais, ${ }^{1}$ Markus Reichstein, ${ }^{4}$ \\ Nicolas Viovy, ${ }^{1}$ André Granier, ${ }^{5}$ Andreas Ibrom, ${ }^{6}$ Pasi Kolari, ${ }^{7}$ Bernard Longdoz, ${ }^{5}$ \\ Eddy J. Moors, ${ }^{8}$ Kim Pilegaard, ${ }^{6}$ Serge Rambal, ${ }^{9}$ Andrew D. Richardson, ${ }^{10}$ \\ and Timo Vesala ${ }^{7}$
}

Received 30 November 2009; revised 1 June 2010; accepted 21 June 2010; published 23 October 2010.

[1] The interannual variability of $\mathrm{CO}_{2}$ exchange by forest ecosystems in Europe was analyzed at site and regional scales by identifying critical periods that contributed to interannual flux anomalies. Critical periods were defined as periods in which monthly and annual flux anomalies were correlated. The analysis was first conducted at seven European forest flux tower sites with contrasting species and climatic conditions. Organizing Carbon and Hydrology in Dynamic Ecosystems (ORCHIDEE), a generic process-based model, represented fairly well most features of the critical period patterns and their climate drivers at the site scale. Simulations at the scale of European forests were performed with ORCHIDEE integrated at a $0.25^{\circ}$ spatial resolution. The spatial and temporal distributions of critical periods for canopy photosynthesis, ecosystem respiration, and net ecosystem exchange (NEE) as well as their underlying climate drivers were analyzed. The interannual variability in gross primary productivity (GPP) was explained by critical periods during spring and summer months. In contrast, the interannual variability in total ecosystem respiration (TER) was explained by critical periods occurring throughout the year. A latitudinal contrast between southern and northern Europe was observed in the distributions of critical periods for GPP and TER. The critical periods were positively controlled by temperature in northern Europe and by soil water availability in southern Europe. More importantly, the latitudinal transition between temperature-driven and water-driven critical periods for GPP varied from early spring to late summer. Such a distinct seasonal regime of critical periods was less clearly defined for TER and NEE. Overall, the critical periods associated with NEE variations and their meteorological drivers followed those associated with GPP.

Citation: le Maire, G., et al. (2010), Detecting the critical periods that underpin interannual fluctuations in the carbon balance of European forests, J. Geophys. Res., 115, G00H03, doi:10.1029/2009JG001244.

\footnotetext{
${ }^{1}$ Laboratoire des Sciences de Climat et de l'Environnement, CEA CNRS UVSQ, Gif-sur-Yvette, France.

${ }^{2}$ UMR Eco\&Sols, Cirad, UPR 80 "Ecosystèmes de plantations," Montpellier, France.

${ }^{3}$ Laboratoire Ecologie, Systématique et Evolution, UMR 8079, Université Paris-Sud, CNRS, AgroParisTech, Orsay, France.

${ }^{4}$ Max-Planck-Institute for Biogeochemistry, Jena, Germany.

${ }^{5}$ UMR INRA-UHP Écologie et Écophysiologie Forestières, INRA Centre de Nancy, Champenoux, France.

${ }^{6}$ Biosystems Department, Risø National Laboratory for Sustainable Energy, Technical University of Denmark, Roskilde, Denmark.

${ }^{7}$ Department of Physics, University of Helsinki, Helsinki, Finland.

${ }^{8}$ Earth System Science - Climate Change, Alterra Wageningen UR, Wageningen, Netherlands.

${ }^{9}$ UMR 5175, DREAM, CEFE, CNRS, Montpellier, France.

${ }^{10}$ Department of Organismic and Evolutionary Biology, Harvard University Herbaria, Harvard University, Cambridge, Massachusetts, USA.

Copyright 2010 by the American Geophysical Union. 0148-0227/10/2009JG001244
}

\section{Introduction}

[2] Carbon exchanges between forest ecosystems and the atmosphere vary on timescales from hours to decades. Temporal variability and spatial variability result from variations in abiotic and biotic factors such as meteorology and climate [e.g., Barr et al., 2004; Ciais et al., 2005; Reichstein et al., 2007a, 2007b], trends in atmospheric composition (e.g., rising $\mathrm{CO}_{2}$, variability in $\mathrm{N}$ deposition) [Magnani et al., 2007], management practices (e.g., harvesting or thinning, fertilization) [Ciais et al., 2008], disturbance (e.g., insect damage, storms, fires, tree disease) and internal ecosystem dynamics (e.g., succession) [Remmert, 1991].

[3] When focusing on temporal variability at the continental level across Europe, it is clear that climatic variability is a predominant control on variability in annual net ecosystem exchange (NEE) [Bousquet et al., 2000; Ciais et al., 2005; Piao et al., 2008]. At large spatial scales, management practices may have less impact on NEE fluctuations from 


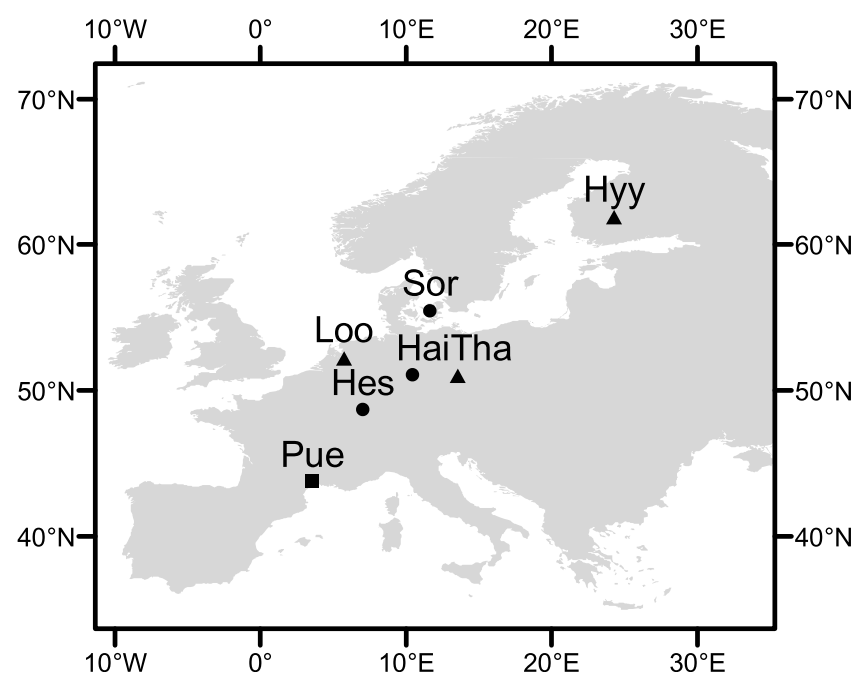

Figure 1. Location of the seven eddy-flux sites used in the study. Triangles represent evergreen needleleaf forest (ENF), circles represent deciduous broadleaf forest (DBF), and square represents evergreen broadleaf forest (EBF) (see Table 1).

one year to the next because these actions are spatially limited, even though some studies suggested that year-toyear changes in wood demand might weakly affect NEE (30 versus $80-130 \mathrm{gC} \mathrm{m}^{-2} \mathrm{a}^{-1}$ ) [Masek and Collatz, 2006]. In some ecosystems (e.g., boreal forests), fire is a major source of year-to-year NEE variability [Amiro et al., 2006; Mouillot and Field, 2005]. Although fire is an important determinant of the carbon balance variability in Mediterranean forests, it can be neglected for the boreal and temperate forest regions of western Europe [van der Werf et al., 2003, 2006].

[4] Net ecosystem exchange is the difference between two large gross fluxes: gross primary productivity (GPP) and total ecosystem respiration (TER). GPP and TER are both positively controlled by temperature and water availability, but have different sensitivities [Kirschbaum, 2000; Reichstein et al., 2002]. Therefore, NEE may be less sensitive to temperature and moisture than GPP and TER individually due to compensation effects [Reichstein et al., 2007b]. The interannual variability of NEE at the ecosystem scale has been attributed to seasonal temperature anomalies [Barr et al., 2007; Black et al., 2000; Chen et al., 2009b; Dunn et al., 2007; Goulden et al., 1998; Hollinger et al., 2004; Suni et al., 2003b; Welp et al., 2007], the amount of spring rainfall [Allard et al., 2008; Ma et al., 2007], summer drought [Aubinet et al., 2002; Goulden et al., 1996; Granier et al., 2007; Mäkelä et al., 2008], snow depth and soil thaw [Goulden et al., 1996; Nobrega and Grogan, 2007], the duration of the growing season [Barr et al., 2007] and leaf loss or damage and forest management [Aubinet et al., 2002; Barr et al., 2004]. At the continental scale, forest inventory data indicate a long-term average carbon sink of $70 \mathrm{gC} \mathrm{m}^{-2} \mathrm{a}^{-1}$ in European forests [Janssens et al., 2003; Nabuurs et al., 2003]. Model studies, including both process-based and remote sensing-driven models, estimate that the interannual variability of that continental sink is on the order of $100 \%$
[Ciais et al., 2005; Reichstein et al., 2007a; Vetter et al., 2008]. Current research tries to better understand and quantify the spatiotemporal variability of carbon fluxes and their controls. Identifying critical seasons that control the interannual variability of $\mathrm{CO}_{2}$ exchanges is important for evaluating the vulnerability of carbon pools and the evolution of future sinks. Processes that lead to this variability range from the rapid photosynthetic responses to meteorological changes to the slow adjustments of carbon and nutrient pools. This implies that the interannual variability of carbon fluxes and the dependence of this variability on climate variables must be studied on a shorter-than-annual time step. Still, it is important to use observation periods of several years with contrasting climatic conditions [Luyssaert et al., 2007]. Long carbon flux measurement records from eddy covariance are still sparse and likely do not provide a representative picture on a continental to global scale, which can be obtained with Terrestrial ecosystem models.

[5] In this paper, we investigated some of the climatic causes of interannual variability of NEE, GPP and TER at the European scale, using the new concept of "critical periods." In short, critical periods for carbon fluxes can be defined as short time periods that affect the long-term fluxes within the ecosystem. In this study, we focused our attention on short (monthly) periods of the year, which largely explained the magnitude of annual anomalies in $\mathrm{CO}_{2}$ fluxes. These critical periods were quantified using statistical criteria detailed in section 2; the main criteria was a significant correlation between the flux anomalies during a critical period and the annual flux anomalies. Initially, the study was carried out for seven eddy flux sites. Critical periods at the European scale were then identified using ORCHIDEE, a processbased ecosystem model [Krinner et al., 2005]. With this contribution, we addressed the following questions: (1) Are annual GPP, TER or NEE flux anomalies in European ecosystems related to specific short periods of the year, called Critical Periods? (2) What are the meteorological drivers underlying these critical periods?

[6] Eddy covariance carbon fluxes at seven European forest sites were analyzed. After testing the ability of the ORCHIDEE model to reproduce carbon flux variability and biotic processes (e.g., budburst and leaf fall dates) at these seven sites, we applied the critical period detection method to the ORCHIDEE model results. Finally, ORCHIDEE was applied at the European scale to analyze regional and seasonal patterns in critical periods.

\section{Material and Methods}

\subsection{Description of Sites and Eddy-Flux Measurements}

[7] Half-hourly eddy-covariance measurements were taken from three evergreen coniferous forest sites, three broadleaved deciduous forest sites and one evergreen broadleaf forest site in the CarboEurope-IP database (http://www. carboeurope.org, Figure 1). These sites were chosen because they had at least 6 years of nearly continuous carbon flux measurements and meteorological observations and because they represented diverse functional types of European forests spanning the European climate gradient (Table 1).

[8] All sites were equipped with sensors to measure air temperature, $\mathrm{CO}_{2}$ and water vapor concentrations and the three components of wind velocity. The covariance of the 
Table 1. Study Site Characteristics ${ }^{\mathrm{a}}$

\begin{tabular}{|c|c|c|c|c|c|c|c|c|c|c|}
\hline Site and Abbreviation & Species & PFT & $\begin{array}{l}\text { Latitude } \\
\quad(\mathrm{N})\end{array}$ & $\begin{array}{l}\text { Longitude } \\
\text { (E) }\end{array}$ & $\begin{array}{c}\text { Age } \\
\text { (years) }\end{array}$ & $\begin{array}{c}\text { EW } \\
(\mathrm{mm})\end{array}$ & $\begin{array}{c}\text { MAT } \\
\text { (C) }\end{array}$ & Years Used & QC & Reference \\
\hline Hyytiälä (Hyy) & Scots pine & ENF & 61.85 & 24.28 & 42 & 125 & 3.5 & $1998-2005$ & 0.95 & Rannik et al. [2002] \\
\hline Sorø (Sor) & European beech & DBF & 55.49 & 11.65 & 83 & 137 & 8.1 & $1998-2005$ & 0.93 & Pilegaard et al. [2001] \\
\hline Loobos (Loo) & Scots pine & ENF & 52.17 & 5.74 & 96 & 135 & 9.8 & $1998-2005$ & 0.89 & Dolman et al. [2002] \\
\hline Hainich (Hai) & European beech & DBF & 51.07 & 10.45 & $0-250$ & 170 & 7 & $2000-2005$ & 0.96 & Knohl et al. [2003] \\
\hline Tharandt (Tha) & Spruce & ENF & 50.96 & 13.57 & 111 & 172 & 7.5 & $1998-2005$ & 0.98 & Grünwald [2003] \\
\hline Hesse (Hes) & European beech & $\mathrm{DBF}$ & 48.67 & 7.08 & 40 & 175 & 10.1 & $1998-2005$ & 0.98 & Granier et al. [2000] \\
\hline Puéchabon (Pue) & Holm oak & $\mathrm{EBF}$ & 43.74 & 3.60 & 61 & 150 & 13.4 & $2000-2005$ & 0.96 & Rambal et al. [2003] \\
\hline
\end{tabular}

${ }^{\mathrm{a}}$ MAT, mean annual temperature; PFT, plant functional type; ENF, evergreen needleleaf forest; DBF, deciduous broadleaf forest; EBF, evergreen broadleaf forest. Maximum extractable water (EW) are from Granier et al. [2007]. Quality check (QC) is the fraction of half-hourly data with good quality with respect to gap-filling after $\mathrm{u}^{*}$-filtering, as assessed by the quality flag equal to 0 or 1 [see Reichstein et al., 2005].

vertical velocity component and the $\mathrm{CO}_{2}$ concentration was computed every half-hour. Meteorological data were continuously measured and averaged every half-hour. Quality checks of the data were done according to CarboEurope-IP guidelines [Aubinet et al., 2000]. Data were gathered within the project database (http://gaia.agraria.unitus.it/database/). Level 4 data used for the study were processed according to standard spike detection, $\mathrm{u}^{*}$-filtering, gap-filling and flux-partitioning algorithms [Papale et al., 2006; Reichstein et al., 2005].

[9] NEE was separated into ecosystem respiration and canopy photosynthesis using the same method for each of the seven sites [Reichstein et al., 2005]. NEE partitioning was based upon an algorithm that first filtered nighttime data to retain measurements acquired when turbulence was well developed and then used the nighttime data to establish the short-term temperature dependence of ecosystem respiration on air temperature. This relationship was then used to extrapolate daytime ecosystem respiration. Canopy photosynthesis was assumed to be equivalent to the difference between ecosystem respiration and net ecosystem exchange.

[10] When available, we used ancillary data for model validation. At four sites (Hesse [Granier et al., 2007], Hyytiälä (S. Sevanto, personal communication. 2010), Tharandt (T. Grünwald, personal communication, 2010), Puéchabon (S. Rambal, personal communication, 2010)) we compared model simulations to measured soil water contents integrated over rooting depth and normalized to relative extractable water as in the work of Granier et al. [2007].

\subsection{Model Description}

[11] ORCHIDEE [Krinner et al., 2005] is a processoriented Dynamic Global Vegetation Model (DGVM) designed to simulate ecosystem energy, water, and carbon fluxes at half-hourly to centennial timescales. ORCHIDEE contains three submodules: a land surface energy and water balance model (SECHIBA [de Rosnay and Polcher, 1998; Ducoudre et al., 1993]), a land carbon cycle model (STOMATE), and a dynamic model of long-term vegetation dynamics including competition and disturbances (adapted from Sitch et al. [2003]). Vegetation is described in terms of twelve plant functional types (PFTs), three of which are relevant for simulations of European forests (Table 1). The vegetation is prescribed either by choosing the PFT that best corresponds to each forest or, for the European-scale simulations, by using a remote sensing-derived vegetation map.

[12] SECHIBA calculates the half-hourly energy and water exchanges of vegetated and nonvegetated surfaces as well as canopy-level photosynthesis using a standard coupling of leaf-level photosynthesis and stomatal conductance modeling [Ball et al., 1987; Farquhar et al., 1980]. Based on soil moisture and root profiles, stomatal conductance is reduced under soil water stress as described by McMurtrie et al. [1990]. SECHIBA considers two soil water reservoirs: a surface reservoir, representing surface wetness in response to rain events, which can often be brought to zero during dry periods; and a deeper reservoir, which acts as a simple bucket model and is updated to account for throughfall, evaporation, root uptake, percolation and runoff.

[13] STOMATE describes autotrophic respiration and soil carbon dynamics at a half-hourly timescale, and plant growth, mortality and phenology at a daily timescale. Plant phenology is based on growing degree days, chilling days, and soil moisture changes specific to each PFT and calibrated using remote sensing data [Botta et al., 2000]. Assimilated carbon is allocated to six plant $\mathrm{C}$ pools (stems, leaves, fruits, carbohydrate reserves, fine roots and coarse roots) and is driven by phenology and environmental stress indices (light availability, temperature and soil water) [Friedlingstein et al., 1999]. Autotrophic respiration is composed of a temperature-dependent maintenance respiration rate and a photosynthesis-dependent growth respiration rate. Litter and soil organic matter decomposition are modeled based on the CENTURY model approach [Parton et al., 1988]. The fire module of the model [Thonicke et al., 2001] was deactivated for the local and regional simulations in this study. We refer to Krinner et al. [2005] and Table 2 for a description of the standard parameter set.

\subsection{ORCHIDEE Simulations Over Europe}

[14] Climate data were obtained from the regional climate model REMO [Jacob and Podzun, 1997] forced with global 6-hourly NCEP (National Centers for Environmental Prediction) reanalysis [Kalnay et al., 1996] from 1948 until the present. The prognostic variables were surface air pressure, temperature, horizontal wind components, specific humidity and cloud water. Hourly values for atmospheric variables were interpolated on a regular latitude-longitude grid with a resolution of $0.25 \times 0.25^{\circ}$ and aggregated to daily values. The REMO model was chosen based on the quality and temporal consistency of its output [Chen et al., 2007]. Climate, soil, land cover forcing and the European-scale simulation protocol are described by Vetter et al. [2008]. The ORCHIDEE model was brought to equilibrium (long-term $\mathrm{NEE}=0$ at each grid point) during a spin-up run forced with preindustrial atmospheric $\mathrm{CO}_{2}(285 \mathrm{ppm})$ by looping through 
Table 2. Parameters of ORCHIDEE, Specific or Not to Main Plant Functional Types of European Forests ${ }^{\mathrm{a}}$

\begin{tabular}{|c|c|c|c|c|c|c|}
\hline \multirow[b]{2}{*}{ Function } & \multirow[b]{2}{*}{ Symbol } & \multirow[b]{2}{*}{ Description } & \multicolumn{4}{|c|}{ Values } \\
\hline & & & All & ENF & $\mathrm{EBF}$ & $\mathrm{DBF}$ \\
\hline \multirow[t]{6}{*}{ Photosynthesis } & $\mathrm{V}_{\mathrm{cmax}, \mathrm{opt}}$ & $\begin{array}{l}\text { optimal maximum rubisco-limited potential } \\
\text { photosynthetic capacity }\left(\mu \mathrm{mol} \mathrm{m} \mathrm{m}^{-2} \mathrm{~s}^{-1}\right)\end{array}$ & - & 35 & 40 & 55 \\
\hline & $\mathrm{T}_{\mathrm{opt}}$ & $\begin{array}{l}\text { optimum, minimum and maximum } \\
\text { photosynthetic temperature }\left({ }^{\circ} \mathrm{C}\right)\end{array}$ & - & 25 & 32 & 26 \\
\hline & $\mathrm{T}_{\min }$ & & - & -4 & -3 & -2 \\
\hline & $\mathrm{T}_{\max }$ & & - & 38 & 48 & 38 \\
\hline & $\mathrm{gs}_{\mathrm{s}}$ & slope of the gs/A relation [see Ball et al., 1987] & 9 & - & - & - \\
\hline & $\mathrm{gs}_{\min }$ & $\begin{array}{l}\text { intercept of the gs/A relation } \\
\text { [see Ball et al., 1987] }\end{array}$ & 0.01 & - & - & - \\
\hline \multirow[t]{9}{*}{ Phenology } & $\mathrm{A}_{\mathrm{c}}$ & mean leaf life span $(d)$ & - & 910 & 730 & 180 \\
\hline & $\lambda_{\max }$ & $\begin{array}{l}\text { maximum LAI beyond which there is no } \\
\text { allocation of biomass to leaves }\end{array}$ & 5 & - & - & - \\
\hline & a & $\begin{array}{l}\text { cumulative degree day threshold calculation } \\
\text { (see equation (A16) of Krinner et al. [2005]) }\end{array}$ & - & - & - & 603 \\
\hline & $\mathrm{b}$ & & - & - & - & 0.0091 \\
\hline & $\mathrm{c}$ & & - & - & - & 64 \\
\hline & $\mathrm{T}_{\mathrm{w}}$ & $\begin{array}{l}\text { daily temperature threshold for summing } \\
\text { cumulated degree days }\left({ }^{\circ} \mathrm{C}\right)\end{array}$ & - & - & - & 5 \\
\hline & SLA & specific leaf area $\left(\mathrm{m}^{2} \mathrm{gC}^{-1}\right)$ & - & 0.01 & 0.02 & 0.026 \\
\hline & $\tau_{\text {leafinit }}$ & time to put initial leaf mass on $(\mathrm{d})$ & 10 & - & - & - \\
\hline & $\mathrm{T}_{\mathrm{s}}$ & $\begin{array}{l}\text { weekly temperature below which leaves } \\
\text { are shed if seasonal temperature trend } \\
\text { is negative }\left({ }^{\circ} \mathrm{C}\right)\end{array}$ & - & - & - & 12.5 \\
\hline \multirow[t]{5}{*}{$\begin{array}{l}\text { Autotrophic } \\
\text { respiration }\end{array}$} & $\mathrm{c}_{\mathrm{mr} \_ \text {leaf }}$ & $\begin{array}{l}\mathrm{c}_{0, \mathrm{i}, \mathrm{j}} \text { and } \mathrm{T}_{0} \text { parameters for the calculation of } \mathrm{c}(\mathrm{T}) \\
\text { in equation (A42) of Krinner et al. [2005] }\end{array}$ & - & $1.01 \mathrm{e}-3$ & $2.35 \mathrm{e}-3$ & $2.62 \mathrm{e}-3$ \\
\hline & $\mathrm{c}_{\mathrm{mr} \text { roots }}$ & & $1.67 \mathrm{e}-3$ & - & - & - \\
\hline & $\mathrm{c}_{\mathrm{mr} \_ \text {sapwood }}$ & & $1.19 \mathrm{e}-4$ & - & - & - \\
\hline & $\mathrm{s}_{\mathrm{mr}}$ & & 16 & - & - & - \\
\hline & $\mathrm{f}_{\mathrm{gr}}$ & $\begin{array}{l}\text { fraction of allocatable biomass which is } \\
\text { lost as growth respiration }\end{array}$ & 0.28 & - & - & - \\
\hline Allocation $^{\mathrm{b}}$ & $\tau_{\text {sapwood }}$ & $\begin{array}{l}\text { rate of conversion from sapwood to } \\
\text { heartwood }(d)\end{array}$ & 730 & - & - & - \\
\hline \multirow{11}{*}{$\begin{array}{l}\text { Heterotrophic } \\
\text { respiration }\end{array}$} & $\tau_{\text {active }}$ & residence times in carbon pools (y) & 0.149 & - & - & - \\
\hline & $\tau_{\text {slow }}$ & & 5.48 & - & - & - \\
\hline & $\tau_{\text {passive }}$ & & 241 & - & - & - \\
\hline & $\mathrm{f}_{\text {active }}=>$ passive & flux fractions between carbon pools & 0.004 & - & - & - \\
\hline & $\mathrm{f}_{\text {active }}=>$ slow & & (function of clay) & - & - & - \\
\hline & $\mathrm{f}_{\text {slow }}=>$ active & & 0.42 & - & - & - \\
\hline & $\mathrm{f}_{\text {slow }}=>$ passive & & 0.03 & - & - & - \\
\hline & $\mathrm{f}_{\text {passive }}=>$ active & & 0.45 & - & - & - \\
\hline & $\mathrm{c}_{\mathrm{H}}$ & $\begin{array}{l}\text { soil temperature inhibition factor } \mathrm{c}_{\mathrm{H}} \text {, } \\
\left(\mathrm{T} \text { is the soil temperature in }{ }^{\circ} \mathrm{C}\right)\end{array}$ & $=2^{(\mathrm{T}-30) / 10}$ & - & - & - \\
\hline & $\mathrm{c}_{\mathrm{H}}$ & $\begin{array}{l}\text { soil humidity inhibition factor } \mathrm{c}_{\mathrm{H}} \\
\text { ( } \mathrm{m} \text { is the soil moisture) }\end{array}$ & $=-1.1 \mathrm{~m}^{2}+2.4 \mathrm{~m}-0.29$ & - & - & - \\
\hline & $\mathrm{Z}_{\text {root }}$ & $\begin{array}{l}\text { exponential depth scale for root length } \\
\text { profile }(\mathrm{m})\end{array}$ & - & 1 & 1.25 & 1.25 \\
\hline
\end{tabular}

${ }^{\mathrm{a} E N F}$, evergreen needleleaf forest; DBF, deciduous broadleaf forest; EBF, evergreen broadleaf forest; all, same value for ENF, DBF, and EBF.

${ }^{\mathrm{b}}$ Other allocations parameters given by Krinner et al. [2005].

one decade of meteorological data (1948-1958). This spin-up run was followed by a transient simulation using meteorological data from 1948 to 2005 and increasing atmospheric $\mathrm{CO}_{2}$.

\subsection{ORCHIDEE Simulations at Eddy-Flux Sites}

[15] ORCHIDEE was brought to equilibrium with cycled REMO meteorology from 1948 to 1958 adjusted to current meteorological data from each flux tower. REMO meteorology was adjusted to site meteorology using site-specific regressions derived from the overlap period in monthly aggregates to avoid errors resulting from the precise timing of the passage of frontal systems. After the equilibrium state was reached, the model was transiently integrated with observed increasing $\mathrm{CO}_{2}$ concentrations and adjusted REMO meteorology for 1948-2005. The final years of the simula- tions coincided with the operating time of the eddy covariance systems. These years were used for the detection of critical periods (Table 1). The ORCHIDEE initialization procedure ensured consistent estimates of carbon fluxes in the model world and avoided the biases from imperfect initialization that may have arisen if information about the site history was unknown. The drawback of this initialization was that, by definition, long-term mean equilibrium NEE is close to 0 (the increasing $\mathrm{CO}_{2}$ levels created a small difference from 0). Therefore, NEE was underestimated if, as is the case for most European forest flux towers, the forests were carbon sinks. The initialization method thus introduced an artificial bias in annual NEE. This bias did not hinder the identification of critical periods, however, because these periods relate to anomalous changes in carbon balances in response to meteorological factors. Note, however, that 
carbon pools must be simulated by the model; models that use climate to calculate GPP and TER without coupling with $\mathrm{C}$ pools may exaggerate $\mathrm{C}$ flux anomalies [see Patra et al., 2008].

[16] In the site-scale hourly simulations, we ignored processes affecting carbon dynamics that were not climatedependent (thinning or natural disturbances) and other process such as emissions of biogenic volatile organic compounds or dissolved organic carbon. For each study site, the maximum extractable soil water was fixed to the site-scale values given by Granier et al. [2007] and the modeled vegetation type was selected to match the actual vegetation. Other parameters are identical to the ones used in the European-scale simulations. Notably, ORCHIDEE can also be optimized for important parameters at the site scale, which would improve the simulations [Keenan et al., 2009; Santaren et al., 2007] at the expense of a loss of model applicability to other sites. As a consequence, we decided not to use site-optimized versions of the model in this study.

[17] We compared the simulated and measured occurrences of phenological events. The onset and end dates of the leafy season for deciduous broadleaf sites were determined in measurements and simulations by fitting two piecewise linear segments to the canopy photosynthesis time series [see Delpierre et al., 2009, Figure 1]. The DoY 1-151 and DoY 250-365 periods were considered the onset and end of the leafy season, respectively. The canopy photosynthesis daily values were first smoothed using 10 day averages to avoid high-radiation related day-to-day variability. This method did not allow for the detection of the end of the leafy season in 2003, when the autumnal canopy photosynthesis time series appeared strongly flattened at all sites following a major drought episode. The intersection of the piecewise model provided values for the onset and the end of the leafy season, which were used to compare model and data phenology.

\subsection{Detection of Critical Periods}

2.5.1. Critical Period Definition and Detection Criteria

[18] We wanted to determine if short periods of the year could explain the magnitude of annual carbon flux anomalies. Our analysis was based on monthly periods, which integrate both the influence of short anomalies (e.g., weather fronts lasting a few days) as well as long-lasting (monthly) anomalies, which are recognized as playing an important role in interannual flux variability [see Ciais et al., 2005; Delpierre et al., 2009]. This time interval also scales with the changes that affect the seasonality of ecosystem functions (e.g., phenological transitions or summer drought occurrence). Because annual fluxes are the sums of monthly fluxes, it was noteworthy that months of the year with high flux levels and high variances had a noticeable effect on both annual fluxes and interannual variability. We were also interested by the covariance between monthly and annual fluxes to find possible origins of interannual variability. This covariance was analyzed through correlation coefficients to normalize the results among sites.

[19] We therefore defined a "Critical period" (CP) as a 1 month-long period that met the following two criteria.

[20] 1. The first criteria (C1) is that the flux anomalies during a critical period were significantly correlated with annual flux anomalies (anomalies = deviations from the long-term average). The calculation of the correlation coefficient was done as follows: for the $n$ years of the time series, $n$ flux anomalies during each month $m\left(F_{m}\right)$ and $n$ annual anomalies $\left(F_{a}\right)$ were calculated and correlated. If the correlation $r$ between monthly and annual anomalies was significant, $\mathrm{C} 1$ was true.

[21] 2. The second criteria (C2) is that the ratio of month $m$ variance $\left(\operatorname{var}_{\mathrm{m}}\right)$ to annual flux variance $\left(\operatorname{var}_{\mathrm{a}}\right)$ over the whole period was greater than 0.01. This criterion was intended to filter out correlations obtained with low variance.

[22] The two criteria to define month $m$ as a critical period for the purposes of this analysis were summarized as:

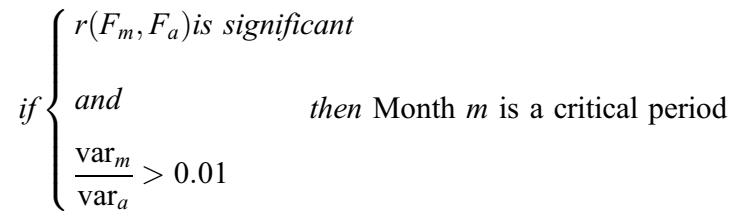

The concept of annual fluxes implied a definition for "a year" for a forest [see also Luyssaert et al., 2007]. The calendar year made little sense because activity generally started at budburst or was triggered by air temperature for boreal needleleaved trees. The dates of onset were variable between sites and years and could not be used to define a forest year. The simplest strategy was to calculate whether $\mathrm{C} 1$ and $\mathrm{C} 2$ were true for each month compared to the annual flux anomaly centered on that month. For instance, the January anomaly was compared to the annual flux anomaly from mid-July of the previous year through the following mid-July. If a data set was $n$ years long, there were $n-1$ candidate years for the detection of critical periods.

[23] Because an annual flux is the sum of twelve monthly fluxes and contains the monthly anomalies used for comparison, there was a chance of spurious correlation. As a consequence, the standard $\mathrm{p}$ value could not be used for testing the significance of correlation ( $\mathrm{r}$ ) for $\mathrm{C} 1$. A simple MonteCarlo approach showed that random data for a 7 year data set had only a $10 \%$ chance of having $r>0.77$ or $r<-0.33$; for a 5 year data set, the thresholds were $r>0.80$ and $r<-0.40$. These $r$ thresholds were therefore adopted to retain periods for which $\mathrm{C} 1$ was true.

[24] The correlation coefficients (r) and their significance were calculated. Results from eddy-flux data and ORCHIDEE simulations were compared using a daily time series and a moving window of 31 days. This method generated 365 daily values of $r$ where the ith value is the correlation between the average flux for the 31 days centered on day $i$ and the annual flux for the 365 days centered on day $i$. The same method was applied to the gridded ORCHIDEE output for 1992-2005, generating 9146 land-grid points. Therefore, the detection of critical periods in European-scale simulations at a resolution of $0.25^{\circ}$ by $0.25^{\circ}$ was based on a longer period than the detection of critical periods at the site scale (see Table 1).

\subsubsection{Meteorological Drivers of Critical Periods}

[25] The second step stage of analysis was intended to identify the meteorological driver that explained the flux anomaly in a given critical period. We expected meteorological variables to directly affect carbon fluxes. Climate anomalies may also be expected to have a lagged influence 
on carbon exchanges through modifications to ecosystem state variables (e.g., living biomass and soil organic matter pools, canopy development, and soil water reserve) [Barford et al., 2001]. We focused on four climate drivers: air temperature $(\mathrm{Ta})$, vapor pressure deficit (VPD), global radiation $(\mathrm{Rg})$, and soil water content (SWC). Although SWC was not a meteorological driver, it integrated information on the soil extractable water, time course of rain events, actual evapotranspiration and runoff. Using SWC thus allowed us to separate wet and water-limited periods while explaining critical periods. Different methodologies, depths, spatial sampling distributions and time steps were used for measuring SWC at each site. Therefore, for consistency among sites, we used ORCHIDEE to simulate SWC for each site level based on a hydrological scheme with a two-bucket daily water balance calculation [Ducoudre et al., 1993]. Therefore, explaining critical periods with SWC was not a model-independent result as it depended on the ability of ORCHIDEE to simulate the soil water balance. This ability was tested at four sites where SWC was measured (HYY, THA, HES and PUE).

[26] Correlation coefficients for climatic drivers and $\mathrm{CO}_{2}$ fluxes for each of the monthly critical periods were calculated for the $n$ years of observation available at each site. For cases with no significant correlation $(\mathrm{p}=0.05$ significance threshold), the critical periods could reflect, for example, the combined effects of meteorological drivers, independent biotic effects or even lagged correlations with climate. One month lagged $r$ values were therefore calculated after removal of the autocorrelation in the meteorological time series by means of partial correlations.

\subsection{Significance of Simulated and Observed Critical Periods}

[27] We examined whether the ORCHIDEE model provides reasonable simulations of site-scale critical periods and their drivers. In addition to directly comparing modeled fluxes with on-site measurements, the ability of ORCHIDEE to reproduce critical periods was estimated with two statistical steps. First, the agreement between measured and modeldetected critical periods at each site was given by Cohen's kappa statistics [Cohen, 1960]. Second, the ability of the model to detect critical periods among sites was estimated by evaluating the number of sites with good model-data agreement out of the seven sites and comparing this score to that which could randomly arise.

[28] The kappa measure of agreement is the ratio:

$$
\kappa=\frac{P(a)-P(e)}{1-P(e)}
$$

where $P(a)$ is the fraction of time when the simulations and observations agree and $P(e)$ is the fraction of time when they could agree by chance alone (i.e., the product of the proportion of detected critical periods in simulated and observed time series). The $\kappa$ statistics considered periods when both simulations and observations agreed that a certain period was either a critical period or not a critical period. Negative $\kappa$ values indicated no agreement, values of $\kappa$ between 0.2 and 0.4 indicated a fair agreement, $0.4<\kappa<0.6$ indicated a moderate agreement and $\kappa>0.6$ a good agreement. The $\kappa$ values are considered significant for $p_{\kappa}<0.05$.
[29] We estimated the probability that ORCHIDEE would simulate sites with significant $\kappa$ values by chance for a population of seven sites. This probability was calculated using a binomial distribution as in the work of Piao et al. [2008, supplementary information]. A successful event was defined as "ORCHIDEE produced a significant critical period at a site." The probability $p_{\kappa}$ of success happening by chance was fixed at 0.05 , the critical threshold of the $\kappa$ statistics. The collective probability $P_{c}$ of achieving $x$ success by chance in the population of seven sites was given by equation (3):

$$
P_{c}(X=x)=C_{7}^{x} \times\left(p_{\kappa}\right)^{x} \times\left(1-p_{\kappa}\right)^{7-x}
$$

where $C_{7}^{x}$ was the binomial coefficient. If the probability of having more than $x$ success by chance was low $(<0.05)$, we concluded that the ORCHIDEE scores were unlikely to reflect chance alone and that the model had the ability to be predictive and to capture the timing of critical periods among sites.

\section{Results and Discussion}

\subsection{Model Validation}

[30] The agreement between simulated $\mathrm{CO}_{2}$ flux time series and data was generally high for both seasonal cycle phase and amplitude (Figure 2) [see also Krinner et al., 2005] and was considered satisfactory for such a generic model.

[31] For sites where SWC data were available, the model was found to effectively reproduce the seasonality of SWC (see Figure 3). High correlation coefficients were found (HES: $\mathrm{r}^{2}=0.87$, HYY: $\mathrm{r}^{2}=0.65$, THA: $\mathrm{r}^{2}=0.71$, PUE: $\mathrm{r}^{2}=$ 0.90). For the three sites where a temporal integration of measured SWC can be done (HES, HYY, THA), monthly SWC anomalies were also very well simulated (average $\mathrm{r}^{2}$ values of $0.96,0.59$ and 0.76 , respectively, for anomalies in the leafy season). These results illustrated the ability of the model to capture summer drought episodes and implied that SWC could be used as a reliable driver to represent site water availability.

[32] We noticed that the modeled phenology was not able to accurately represent the sharp spring transition between the dormant and leafy seasons in deciduous forests (Figure 4), which was confirmed by LAI measurements using intercepted radiation (not shown). The rigid PFT-specific set of phenological parameters used by ORCHIDEE to determine the onset of the leafy season for deciduous forests [Botta et al., 2000] was likely not suitable for representing intersite variability. On the contrary, the autumnal end of the leafy season was correctly simulated $\left(\mathrm{r}^{2}\right.$ values ranged from 0.40 in SOR to 0.82 in HAI). We therefore expected that the positions of the critical periods driven by leafing were uncertain within several weeks and that the principal seasonal pattern was not affected.

\subsection{Critical Periods for Flux Variability at the Site Level}

\subsubsection{Critical Periods in Measurements}

[33] Figure 5 shows the critical periods as detected in measured time series at each site (black lines). The critical periods for GPP $\left(\mathrm{CP}_{\mathrm{GPP}}\right)$ were detected at the beginning of 


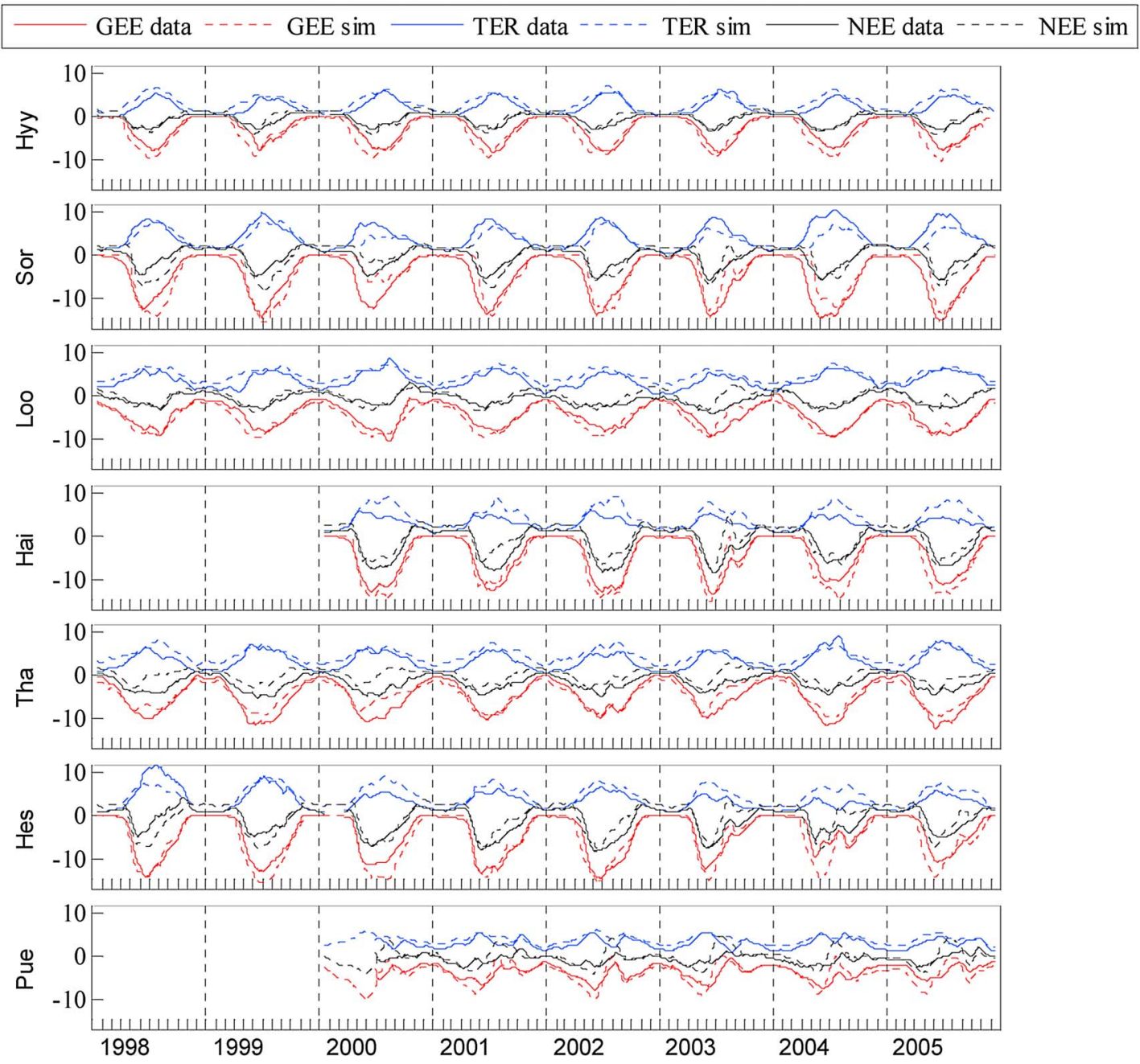

Figure 2. Comparison of carbon fluxes obtained using the model and measurements. For readability, the gross ecosystem exchange (GEE) is shown instead of GPP, with GEE $=-$ GPP (monthly averages, gC. $\left.\mathrm{m}^{-2} \mathrm{a}^{-1}\right)$.

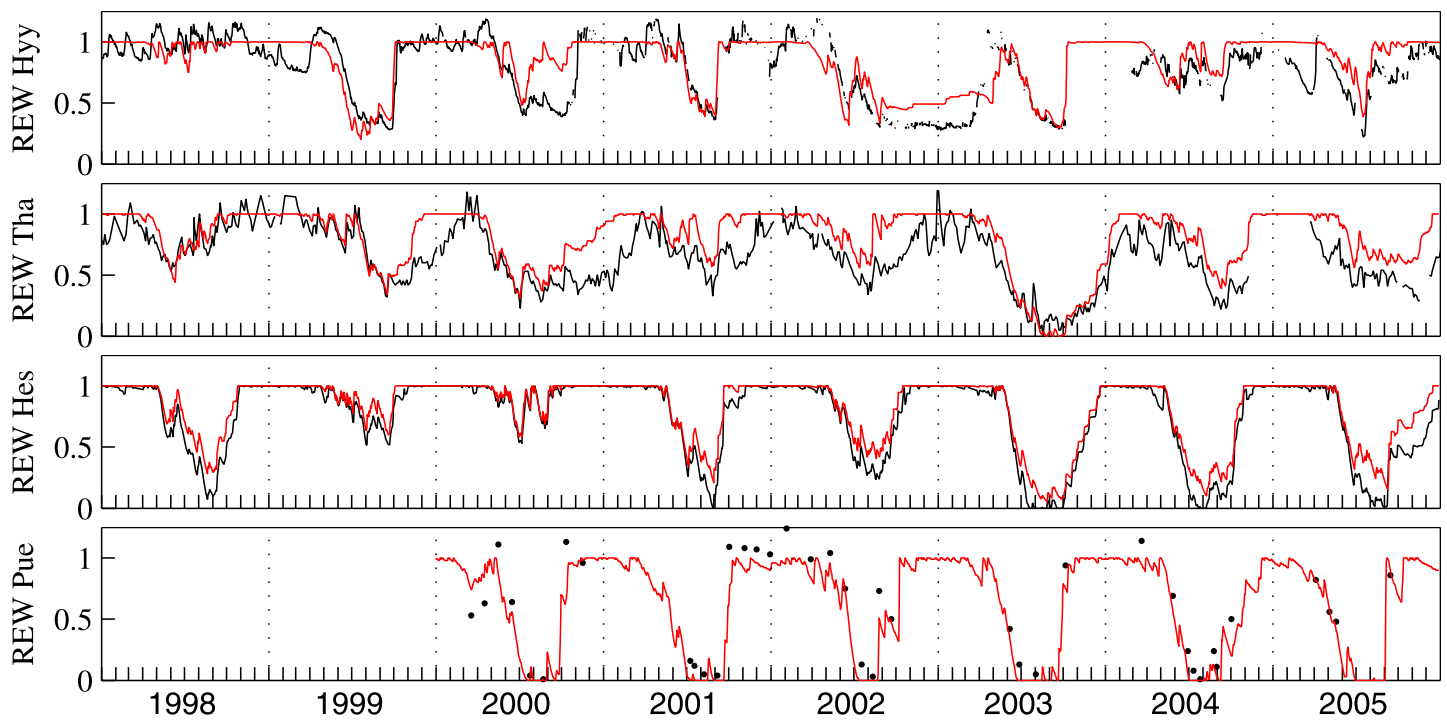

Figure 3. Model-data comparison of relative extractable water (REW). ORCHIDEE simulations are in red, and data are in black. 

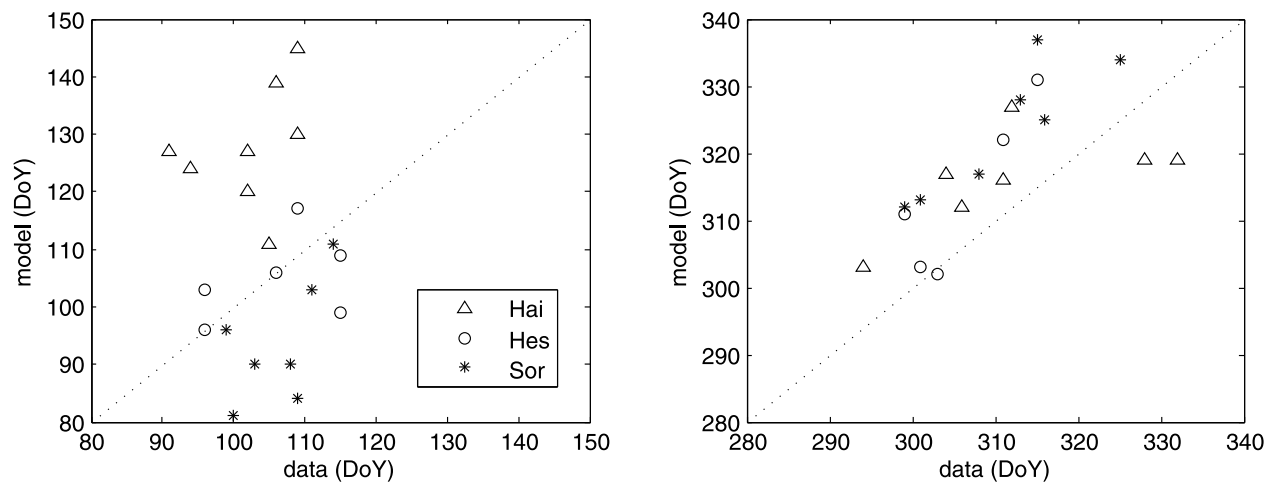

Figure 4. Model-data comparison of (left) onset and (right) end dates (DoY) of the leafy season calculated from the simulated and measured GPP transition (see text). The identity line is dashed.

the growing season (DoY 90-140) in the LOO pine forest (Netherlands). $\mathrm{CP}_{\mathrm{GPP}}$ were evenly distributed during the entire growing season in the THA spruce forest (Germany) and in the HYY pine forest (Finland). The three temperate beech forests showed a distinct $\mathrm{CP}_{\mathrm{GPP}}$ distribution throughout the season. $\mathrm{CP}_{\mathrm{GPP}}$ at beech sites were detected in the summer and early autumn (HES, eastern France, SOR, Denmark, HAI, Germany) and in the spring (SOR). At the
Mediterranean holm oak forest site (PUE) in southern France, $\mathrm{CP}_{\mathrm{GPP}}$ occurred between DoY 150 and 260. At nearly all sites, the correlations between $\mathrm{CP}_{\mathrm{GPP}}$ and annual GPP anomalies were positive. An exceptional negative correlation was observed near the end of the growing season at HYY. The monthly variance of this period represented $7 \%$ of the annual variance. A potential mechanism for explaining the negative correlation at HYY in autumn was the coincidence
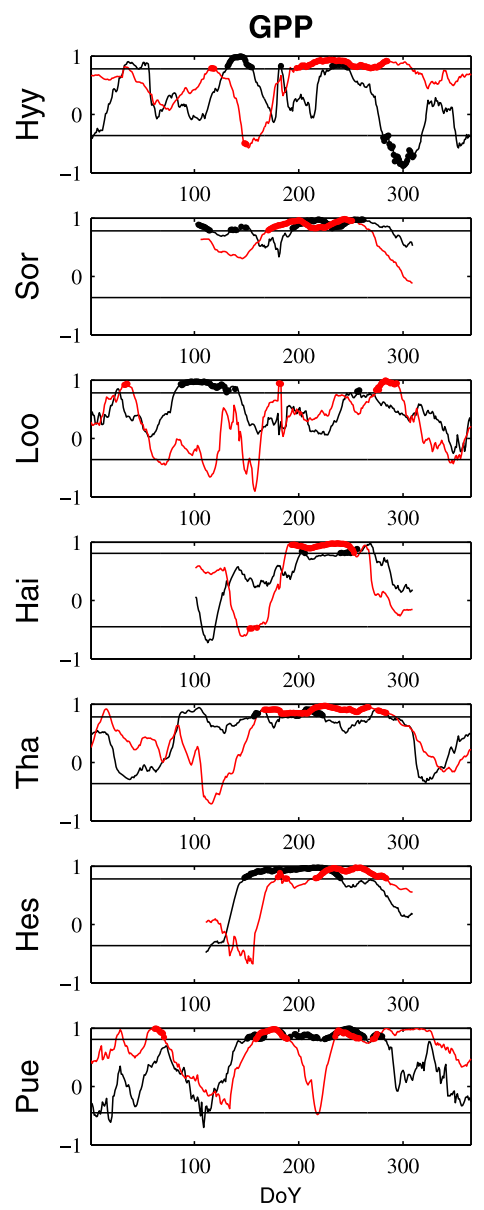

TER
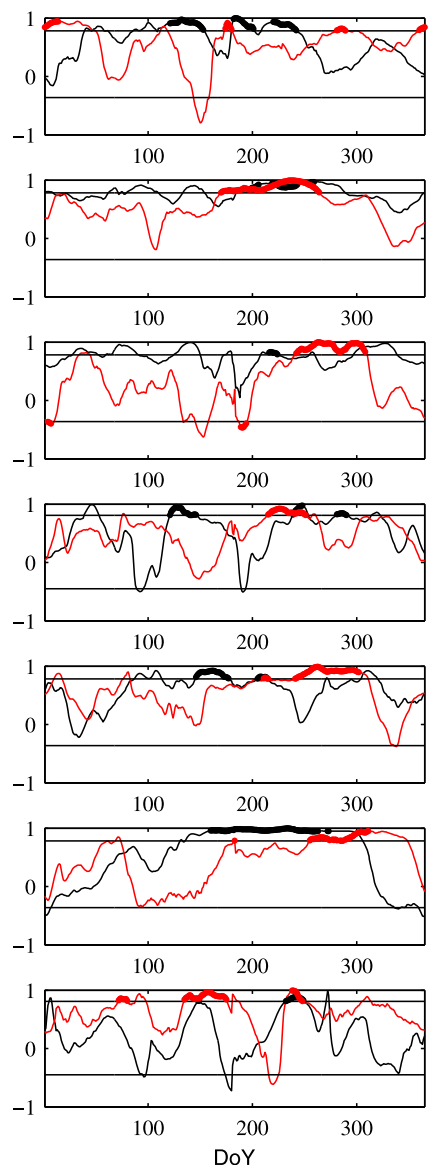
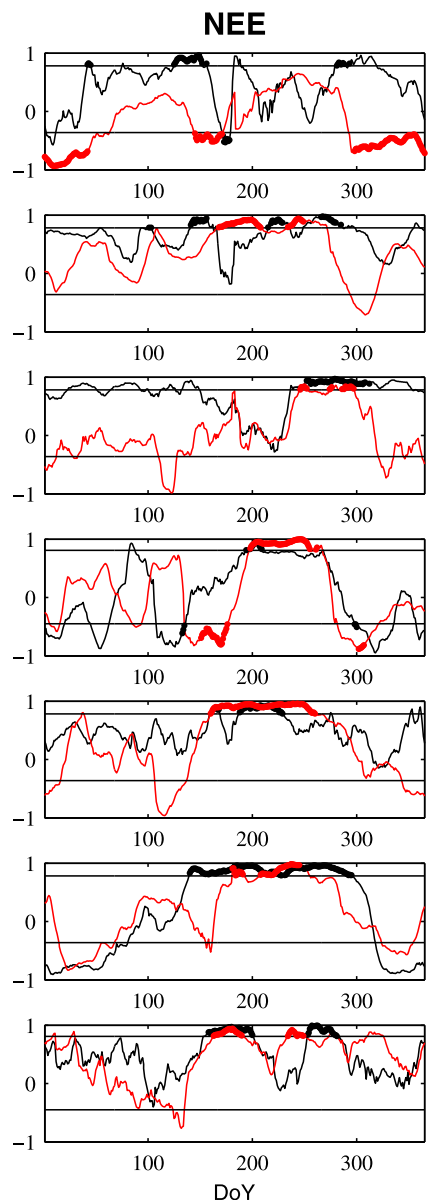

Figure 5. Moving correlation coefficients between monthly and annual NEE, GPP, and TER at seven CarboEurope sites. Flux tower measurements (black) and ORCHIDEE model simulations (red) are calculated from 6 to 8 years of data (see Table 1). Thick lines identify critical periods. 
Table 3. Values of Cohen's Kappa $(\kappa)$ With Significance Index ${ }^{a}$

\begin{tabular}{cccccccc}
\hline & Hyy & Sor & Loo & Hai & Tha & Hes & Pue \\
\hline GPP & 0.09 & $0.57^{*}$ & -0.11 & 0.12 & $0.40^{*}$ & $0.19^{*}$ & $0.32^{*}$ \\
TER & -0.13 & $0.51^{*}$ & -0.05 & $0.19^{*}$ & -0.08 & -0.05 & $0.22^{*}$ \\
NEE & -0.11 & -0.16 & $0.34^{*}$ & $0.15^{*}$ & $0.55^{*}$ & $0.33^{*}$ & $0.39^{*}$ \\
\hline
\end{tabular}

${ }^{a}$ Asterisks indicate if $\mathrm{p}_{\kappa}<0.05$. Values of $\kappa$ reflect the ability of the ORCHIDEE-simulated critical periods time series to match observations. Negative and zero $\kappa$ values are obtained when there is no agreement. Values between 0 and 1 represent a gradient of agreement between the two series (from no agreement at 0 to perfect agreement at 1$)$.

of low $\mathrm{Ta}$ and high $\mathrm{Rg}$ (anticyclonic conditions). After mid-October, Pinus sylvestris was actively assimilating and responding positively to $\mathrm{Rg}$, albeit at a much lower yield than during the peak growing season. Autumn Ta (DoY 270-335) was found to be positively correlated to annual Ta (data not shown). Therefore, the combination of low Ta and high Rg, which drove high autumnal canopy photosynthesis, was generally associated with low annual Ta (low annual GPP anomaly).

[34] $\mathrm{CP}_{\mathrm{TER}}$ were more evenly distributed than $\mathrm{CP}_{\mathrm{GPP}}$ throughout the growing season because the seasonal duration of ecosystem respiration activity was longer than the duration of canopy photosynthesis. Several periods of the year therefore played an important role in controlling TER interannual variability. Finally, $\mathrm{CP}_{\mathrm{NEE}}$ indicated the most important month for the annual carbon balance variability (Figure 5). At four out of seven forest sites (THA, HAI, HES and $\mathrm{PUE}$, $\mathrm{CP}_{\mathrm{NEE}}$ were found only during the growing season. At three other sites (HYY, SOR and LOO) $\mathrm{CP}_{\mathrm{NEE}}$ were found near the margins of the growing season.

\subsubsection{Comparison of Simulated and Observed Critical Periods}

[35] Figure 5 further illustrates the seasonal distribution of critical periods modeled by ORCHIDEE for each site. A comparison of modeled with observed critical periods allowed an assessment of whether critical periods could be captured. Overall, the model was able to simulate observed $\mathrm{CP}_{\mathrm{GPP}}$ with $\kappa>0.2$ (fair agreement) for four sites out of seven (Table 3 ). For the THA and HYY sites, $\mathrm{CP}_{\mathrm{GPP}}$ occurring at the middle and end of the growing season were correctly located by the model. However, the model did not capture the early growing season $\mathrm{CP}_{\mathrm{GPP}}$ at THA, HYY, or LOO due to a bias in phenology (as discussed earlier, see Figure 2). At LOO, this failure could also be due to the fact that GPP of the herbaceous understory was not simulated. The $\mathrm{CP}_{\mathrm{GPP}}$ simulation was poor at HYY $(\kappa=0.09)$, and the model was not able to reproduce observed negative autumnal correlations. On average, the model accurately located the $\mathrm{CP}_{\mathrm{GPP}}$ in the deciduous forests (SOR: $\kappa=0.57$; HES: $\kappa=0.19$; HAI: $\kappa=0.12$, but for this last site $\kappa$ was very sensitive to the significance threshold: $\kappa=0.3$ for a significance threshold of 0.11 instead of 0.1 in equation (1)). In the early season at SOR, the error probably came from the nonmodeled herbaceous strata. At the Mediterranean holm oak forest (PUE), the simulated $\mathrm{CP}_{\mathrm{GPP}}$ also matched $(\kappa=0.32)$ observations except in midsummer (DoY 200-230). This shortcoming in the model reflected excessive water consumption, which overdepleted the soil water content each year during this period (Figures 2 and 3). Excessive depletions could have been caused by the use of a generic rather than a site-specific formulation of stomatal conductance as a function of SWC.
Keenan et al. [2009] recently showed that fitting the response of the dependency of photosynthetic capacity on soil water content variations helped to improve the ORCHIDEE simulation of canopy photosynthesis at PUE. Here, we used the standard version of the ORCHIDEE drought stress simulation. The overestimated water consumption caused only a slight bias in monthly summer canopy photosynthesis. Therefore, the summertime GPP interannual variability was dampened. Compared to GPP, NEE critical periods were more sensitive to the length of the drought stress period (DoY before 200 and after 230).

[36] ORCHIDEE was not as effective for locating $\mathrm{CP}_{\mathrm{TER}}$ as it was for $\mathrm{CP}_{\mathrm{GPP}}$ (3 sites with $\kappa>0.19$, Table 3$)$, due to the multiplicity of processes controlling ecosystem respiration (i.e., autotrophic and heterotrophic processes), their different responses to varying meteorology, and probably the difficulty in obtaining reliable estimates of ecosystem respiration from flux-tower data [see, e.g., van Gorsel et al., 2009]. The simulated $\mathrm{CP}_{\mathrm{TER}}$ and $\mathrm{CP}_{\mathrm{GPP}}$ showed similar patterns because of the growth respiration response, which closely paralleled canopy photosynthesis in ORCHIDEE, and in the modeled direct response of respiration to temperature. On the other hand, $\mathrm{CP}_{\mathrm{TER}}$ in winter were due only to variations in heterotrophic and maintenance respiration processes (see HES in Figure 5).

[37] As for the field data, $\mathrm{CP}_{\mathrm{NEE}}$ reflected the superimposed responses of TER and GPP. Any model error in simulating the gross flux response to climate thus worsened the model's ability to capture $\mathrm{CP}_{\mathrm{NEE}}$. This was seen at HYY, for example, in Figure 5 with $\kappa<0$. However, the $\kappa$ statistics showed that, for most of the sites, the $\mathrm{CP}_{\mathrm{NEE}}$ model-data agreement was fair (3 sites, Table 3 ) or moderate (2 sites).

[38] One explanation for the differences between the simulated and observed critical periods shown in Figure 5 could be that the model did not account for variations in woody biomass, soil carbon stocks or LAI following thinning or defoliation (i.e., nonclimatic or age-related changes). The HYY, THA, HES, and SOR forests were thinned or otherwise affected by severe storms during the observation period, which induced an increase in interannual flux variability that was not incorporated by the model. Vesala et al. [2005] showed that a thinning event removing $25 \%$ of the basal area at the HYY Pine forest (Finland) in spring 2002 had no significant effects on NEE due to the compensating effects of ecosystem respiration and canopy photosynthesis and the enhancement of understory photosynthesis. Thinnings at HES during the winters of 1998-1999 and 2004-2005, in which $25 \%$ of the basal area was cut, did not result in any strong reduction in NEE or GPP at stand scale [Granier et al., 2008]. However, defoliation by Lymanthria dispar at Puechabon led to a 15\% drop in GPP in 2004 [Allard et al., 2008]. 
Table 4. Ability of the ORCHIDEE Model to Simulate Significant Correlation Between the Critical Period Fluxes (for GPP, TER, or NEE) and Meteorology (Ta, SWC, VPD, and Rg) Based on Kappa Statistics ${ }^{\mathrm{a}}$

\begin{tabular}{lcccccccc}
\hline & CP Flux & Hyy & Sor & Loo & Hai & Tha & Hes & Pue \\
\hline Ta & GPP & X & X & & & X & X & X \\
& TER & X & X & & X & X & X & \\
\multirow{4}{*}{ SWC } & NEE & X & & X & & X & X & X \\
& GPP & & X & X & X & & X & X \\
& TER & X & X & & & & X & X \\
\multirow{4}{*}{ VPD } & NEE & X & & & X & X & & X \\
& GPP & & X & X & & X & X & X \\
& TER & & & X & X & X & X & \\
\multirow{2}{*}{ Rg } & NEE & X & X & & X & X & & \\
& GPP & X & X & & & X & X & X \\
& TER & X & & X & X & X & & X \\
& NEE & & & X & X & & X & X \\
\hline
\end{tabular}

${ }^{\mathrm{a}}$ Crosses indicate if $\mathrm{p}_{\kappa}<0.05$.

Therefore, we could not conclude whether the differences between modeled and simulated critical periods can be attributed to thinning or defoliation episodes or to limitations in model parameterizations.

[39] Other model shortcomings for identifying the critical periods may be caused by the changing NEE footprints during the year [Chen et al., 2009a] or by unresolved seasonal errors in the partitioning between ecosystem respiration and canopy photosynthesis. The results presented here compare carbon flux simulations with either gap-filled measurements (in the case of NEE) or statistically separated [Reichstein et al., 2005] gap-filled time series (canopy photosynthesis, ecosystem respiration). In the latter case, we were therefore essentially comparing the results of two models (the ORCHIDEE process-based model versus statistically partitioned gross fluxes). Desai et al. [2008] had shown on a range of sites and years that different flux-separation methods converged to similar monthly sums. This tended to confirm that the statistical separation of canopy photosynthesis and ecosystem respiration did not affect the detection of critical periods in the data. Further, Moffat et al. [2007] showed that structurally different gap-filling schemes yielded similar results for annual NEE sums. However, one should keep in mind that the definition of canopy photosynthesis as the difference between ecosystem respiration and net carbon exchange introduces a spurious correlation between both elementary fluxes [Vickers et al., 2009b]. Any error in the estimation of ecosystem respiration yields a similar uncertainty in the estimate of canopy photosynthesis. The comparison of elementary modeled and partitioned fluxes can therefore best be considered an assessment of the plausibility of model estimation (see also the discussion by Ibrom et al. [2006]).

[40] Independently from the chosen flux separation method, random and systematic errors exist in the data [Hollinger and Richardson, 2005; Kruijt et al., 2004; Richardson et al., 2008; Vickers et al., 2009a], and advection-induced bias can occur even at sites with gentle slopes [Feigenwinter et al., 2008; Kutsch et al., 2008; van Gorsel et al., 2009]. These errors were reduced through $\mathrm{u}^{*}$-filtering but remain inherent to this type of data.

[41] Only three out of seven sites had a significant $\kappa$ for TER critical periods $(p<0.05)$, compared to four and five sites for GPP and NEE, respectively (Table 3 ). Based on equation (3), the probability of obtaining three or more successes out of seven sites by chance was $3.710^{-3}$. We concluded from this that the critical periods reproduced by ORCHIDEE were very unlikely to reflect only chance.

\subsubsection{Comparison of Simulated and Observed Critical} Periods With Meteorological Drivers

[42] The levels of agreement between model results and data based on kappa statistics are provided in Table 4 . Crosses indicate if ORCHIDEE significantly identifies the meteorological drivers that determine the observed critical periods.

[43] For at least four of the seven sites, the model significantly captured the drivers of the observed critical periods (Table 4). According to equation (3), the probability that four or more of seven values would be significant by chance was very unlikely $\left(1.910^{-4}\right)$. Therefore, we concluded that, overall (though not for a particular site), the model was able to attribute critical periods to the correct climate drivers.

[44] The model correctly reproduced the $r$ significance between $\mathrm{CP}_{\mathrm{GPP}}$ and Ta or SWC; five of the seven sites had significant $\mathrm{r}$. The overall correlations between $\mathrm{CP}_{\mathrm{TER}}$ and $\mathrm{Ta}$ were also well simulated, although the $\mathrm{CP}_{\mathrm{TER}}$ for a given site was not always well captured (Table 3 ). The agreement between simulated and measured $\mathrm{r}$ for $\mathrm{CP}_{\mathrm{TER}}$ and $\mathrm{SWC}$ was lower (four significant sites out of seven). The agreement between modeled and measured correlations between $\mathrm{CP}_{\mathrm{NEE}}$ and SWC was low (four out of seven sites) but significant, and the correlation between $\mathrm{CP}_{\mathrm{NEE}}$ and Ta was significantly reproduced by the model for five out of seven sites. When we used ORCHIDEE gridded results to simulate critical periods at the European scale in section 3.3, these limitations became significant.

[45] After demonstrating relatively good agreement between measured and modeled fluxes and ancillary variability (section 3.1), we showed (section 3.2) that ORCHIDEE was also able to reproduce the basic features of the detection patterns for critical periods. ORCHIDEE, a PFTparameterized DGVM, performed reasonably well at simulating fluxes and identifying critical periods at the site scale, although results are more significant for GPP and NEE than for TER. Agreement was within the expected boundaries that were widened due to the use of generic rather than sitespecific parameters. Using site-specific parameters was not possible in a continental simulation. However, the comparisons enhanced our confidence in the overall ability of ORCHIDEE to simulate realistic spatiotemporal patterns in critical periods at the continental scale, as described below.

\subsection{Mapping the Critical Periods of Variability Across Europe}

\subsubsection{Spatial and Seasonal Distribution of Critical Periods}

[46] We applied the critical period detection algorithm that had been developed at site level to each European grid point in the ORCHIDEE simulation. Figure S1 (available as auxiliary material) provides a map of the correlation coefficients (r) between monthly critical periods and annual fluxes. ${ }^{1}$ Figure S1 indicated that the locations of critical

\footnotetext{
${ }^{1}$ Auxiliary materials are available in the HTML. doi:10.1029/ 2009JG001244.
} 

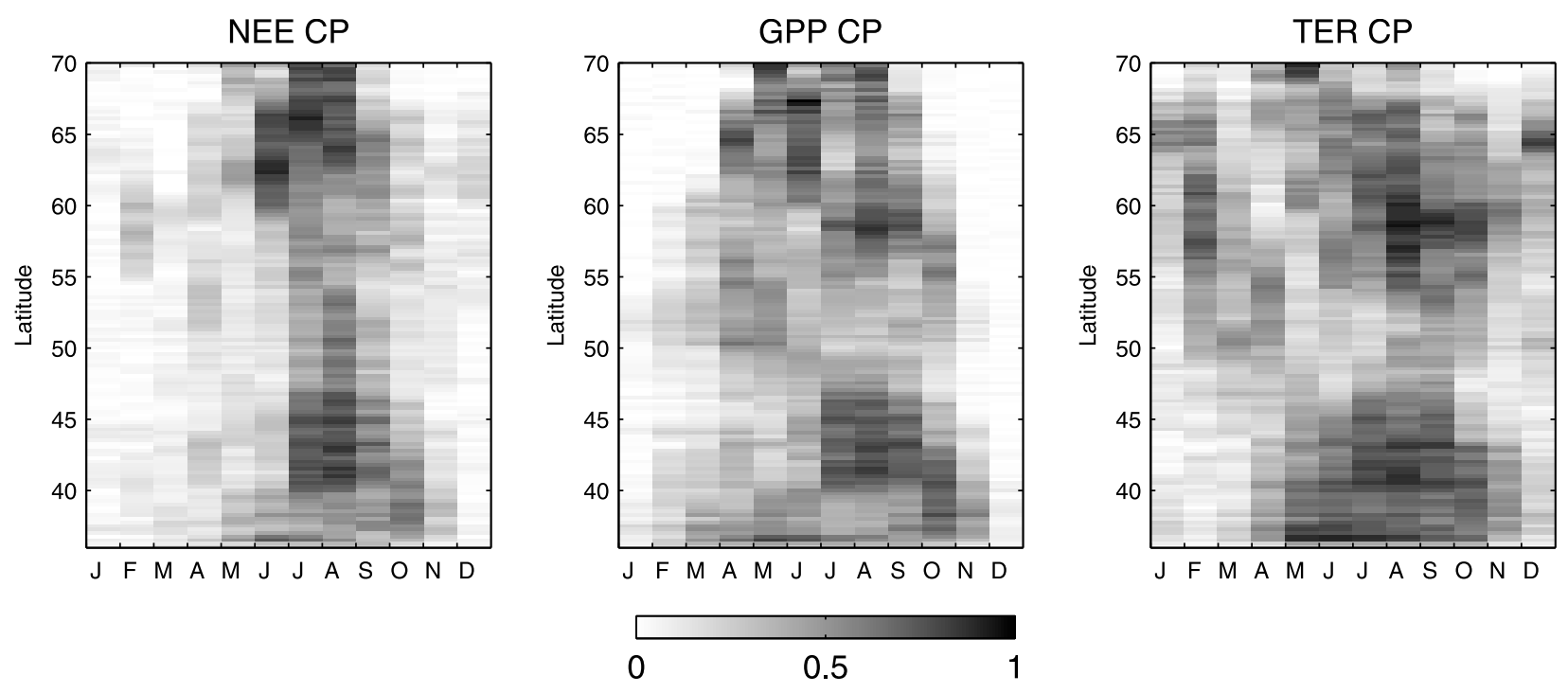

Figure 6. Proportion of ORCHIDEE-modeled forest critical periods for a given month and latitude $\left(0.25^{\circ}\right.$ grid $)$, calculated from 14 years of simulations (1992-2005). Note that zonal averaging accounts for the percentage of forest in each latitudinal strip.

periods were rather latitudinally homogeneous across Europe. This facilitated the creation of a more condensed representation of the critical period maps as a Hovmöller-like diagram by calculating the zonal average of $r$ as a function of time of the year (Figure 6).

[47] $\mathrm{CP}_{\mathrm{GPP}}$ were predominately distributed in the spring and summer months across Europe (Figure 6) and particularly at high latitudes. Because the average values and variability of canopy photosynthesis are higher in spring and summer, anomalies during these two seasons explained most of annual anomalies. Interestingly, spring $\mathrm{CP}_{\mathrm{GPP}}$ were dominant in central European forests between $50^{\circ} \mathrm{N}$ and $55^{\circ} \mathrm{N}$, which reflected the critical influence of canopy photosynthesis during the early growing season in the annual $\mathrm{C}$ balance (exemplified in detailed site studies [e.g., Delpierre et al., 2009; Welp et al., 2007]. Phenology-related $\mathrm{CP}_{\mathrm{GPP}}$ also occurred during the senescence period in October over central European deciduous forests. Over Mediterranean forests (south of $45^{\circ} \mathrm{N}$ ), by contrast, $\mathrm{CP}_{\mathrm{GPP}}$ were located throughout the year due to the dampened seasonality of the annual canopy photosynthesis cycle in these regions [e.g., Allard et al., 2008; Falge et al., 2002].

[48] The distribution of $\mathrm{CP}_{\mathrm{TER}}$ was similar to that of $\mathrm{CP}_{\mathrm{GPP}}$ throughout the annual cycle, but $\mathrm{CP}_{\mathrm{TER}}$ were more frequent than $\mathrm{CP}_{\mathrm{GPP}}$ (Figure 6). The summer months were crucial for $\mathrm{CP}_{\mathrm{TER}}$ over most European forests, illustrating the temperature dependence of respiratory processes in the model. The main differences between the patterns of critical periods of GPP and TER occurred from November to February. Interestingly, these winter months could thus be critical periods for TER, especially north of $50^{\circ} \mathrm{N}$ (Figure 6), despite having lower respiration activity than summer months. The rather even distribution of $\mathrm{CP}_{\mathrm{TER}}$ throughout the annual cycle was partly caused by the fact that the distribution of variance in ecosystem respiration throughout the year is more homogenous than GPP. This enhanced the probability that a given month would account for a high proportion of the annual TER anomaly. Moreover, the model had built-in linkages between TER and GPP that stemmed from (1) the similar response of each gross flux to meteorology (both are sensitive to temperature), (2) growth respiration, which declined with canopy photosynthesis in the model equations or (3) litter production, which fed heterotrophic respiration (HR) and implied a lagged covariation between GPP and HR.

[49] Because NEE was the difference between TER and GPP, $\mathrm{CP}_{\mathrm{NEE}}$ were not systematically reflected in $\mathrm{CP}_{\mathrm{GPP}}$ and $\mathrm{CP}_{\mathrm{TER}}$. Compensatory processes were thus indicated in the variability of gross fluxes, underlining the complex nature of interannual NEE variability. For instance, at the margins of the growing season in European forests (April, May and October), we observed fewer $\mathrm{CP}_{\mathrm{NEE}}$ than $\mathrm{CP}_{\mathrm{GPP}}$ or $\mathrm{CP}_{\mathrm{TER}}$ because GPP and TER covaried positively [see Barr et al., 2007; Delpierre et al., 2009].

[50] In general, a higher number of $\mathrm{CP}_{\mathrm{NEE}}$ appeared during the summer (June-September) when both gross fluxes were high and strongly variable (as exemplified by the concomitant high frequency of $\mathrm{CP}_{\mathrm{GPP}}$ and $\mathrm{CP}_{\mathrm{TER}}$ ). This observation is in line with the well characterized seasonality of $\mathrm{C}$ fluxes in forest ecosystems [e.g., Falge et al., 2002].

\subsubsection{Major Meteorological Drivers} at the Continental Scale

[51] Significant correlations were found between meteorology and critical periods in $\mathrm{CO}_{2}$ flux anomalies in the European simulations. Analysis at the grid point scale (Figure S1) showed that the correlations between critical flux periods and climate were regionally coherent as a function of latitude in Europe, justifying the use of zonal averages for the correlation between monthly critical period flux and Ta, SWC, (Figures 7 and 8), Rg and VPD (Figures S2 and S3) drivers. In the averaging process, the correlation coefficients (r) were weighted by 1 or 0 for critical and noncritical periods, respectively; in other words, only critical period pixels are considered. Note that the correlation maps for VPD mainly followed those obtained for Ta because VPD covaried strongly with Ta (Figure S4). Correlation maps for Rg were similar to those for Ta, but $\mathrm{Rg}$ was positively 
Ta
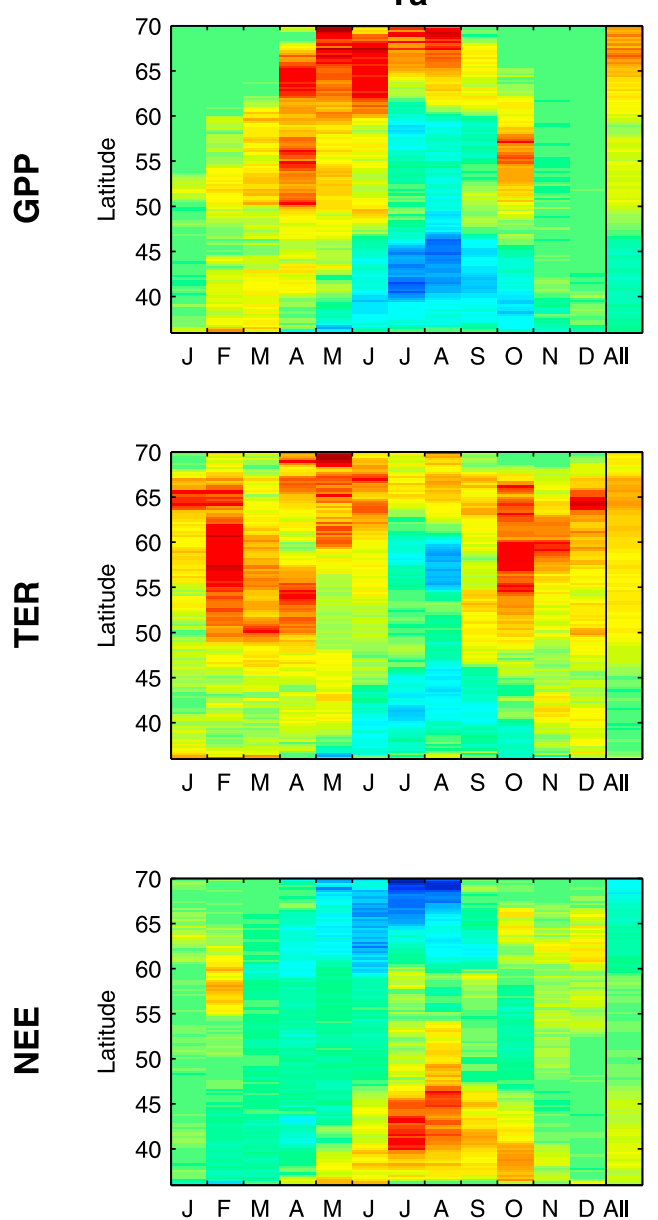

SWC
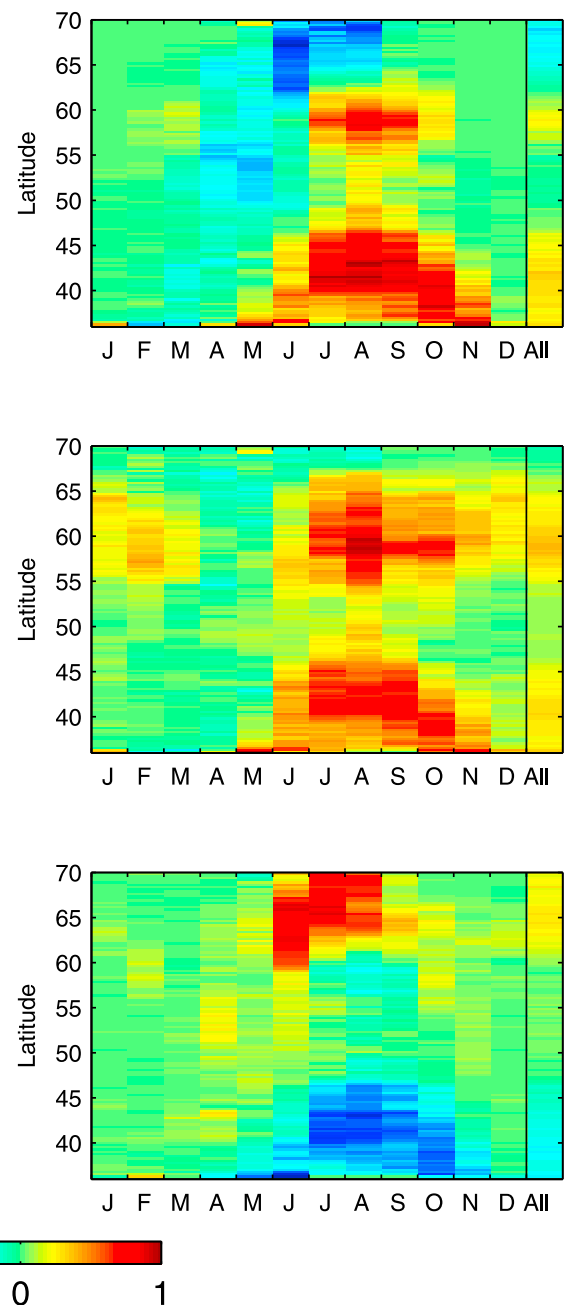

Figure 7. Mean correlation between ORCHIDEE-modeled fluxes (GPP, TER, or NEE) and drivers (Ta or SWC) for a given month and latitude over Europe, weighted by 1 or 0 for critical and noncritical periods, respectively. Calculations utilize 14 years of simulations (1992-2005).

correlated with Ta in summer for most of Europe and negatively correlated with Ta in winter over northern Europe due to anticyclonic conditions (Figure S4).

\subsubsection{GPP}

[52] The predominant drivers of critical period variability of GPP were identified as temperature in northern forests and soil moisture in southern (Figure 7, "all"). In a preceding work contrasting the interannual variability of the dependence of flux on climate using site-scale data analysis, Reichstein et al. [2007b] reported that GPP annual sums shift from SWC to Ta dependency at around $52^{\circ} \mathrm{N}$. In another study, Jung et al. [2007b] showed that three biophysical models (i.e., Biome-BGC, LPJ and ORCHIDEE) identified a shift around the pivotal $60^{\circ} \mathrm{N}$ band from negative (southward) to positive (northward) influences of high radiation, temperature and VPD and low rainfall on summer (June-August) GPP anomalies.

[53] Our critical period analysis corroborated the findings of Reichstein et al. [2007b] and Jung et al. [2007b] (Figure 7) and further extended these findings from spatial to temporal variability regimes.
[54] In Figure 7, the GPP annual anomalies appeared to be driven by temperature from May to October in northern Europe and by SWC from July to October in southern Europe. The latitudinal boundary between Ta and SWC limitation appeared to be dynamic and shifted to the north from May to July. The maximum latitude at which SWC was sufficiently influential to explain the interannual variability of GPP during the study period was roughly $60^{\circ} \mathrm{N}$ in July. This SWC control boundary moves to the south $\left(40^{\circ} \mathrm{N}\right)$ in October. For temperate forest ecosystems located between $45^{\circ} \mathrm{N}$ and $60^{\circ} \mathrm{N}$, the simulated GPP annual anomalies were controlled by temperature in spring, by SWC in summer, and by temperature again in autumn. For SWC, a second maximum occurred in summer around $60^{\circ} \mathrm{N}$ due to a continental effect, as most of the area has a continental climate at this latitude.

[55] In the model, the existence of GPP annual anomalies can be positively correlated with temperature in spring because the temperature used in leaf photosynthesis equations is suboptimal in spring and because phenological processes are dependent on temperature. The negative correlation between 
$\mathrm{Ta}$
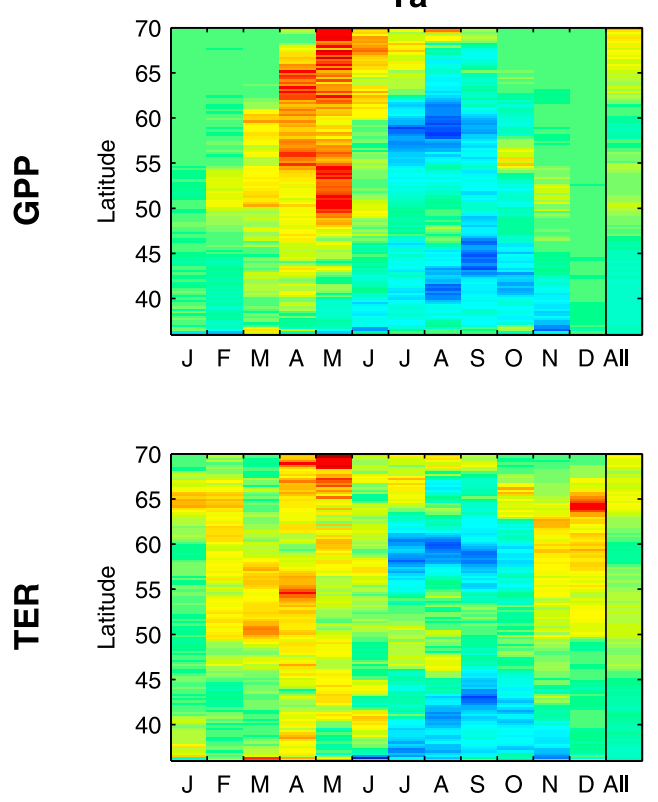

SWC
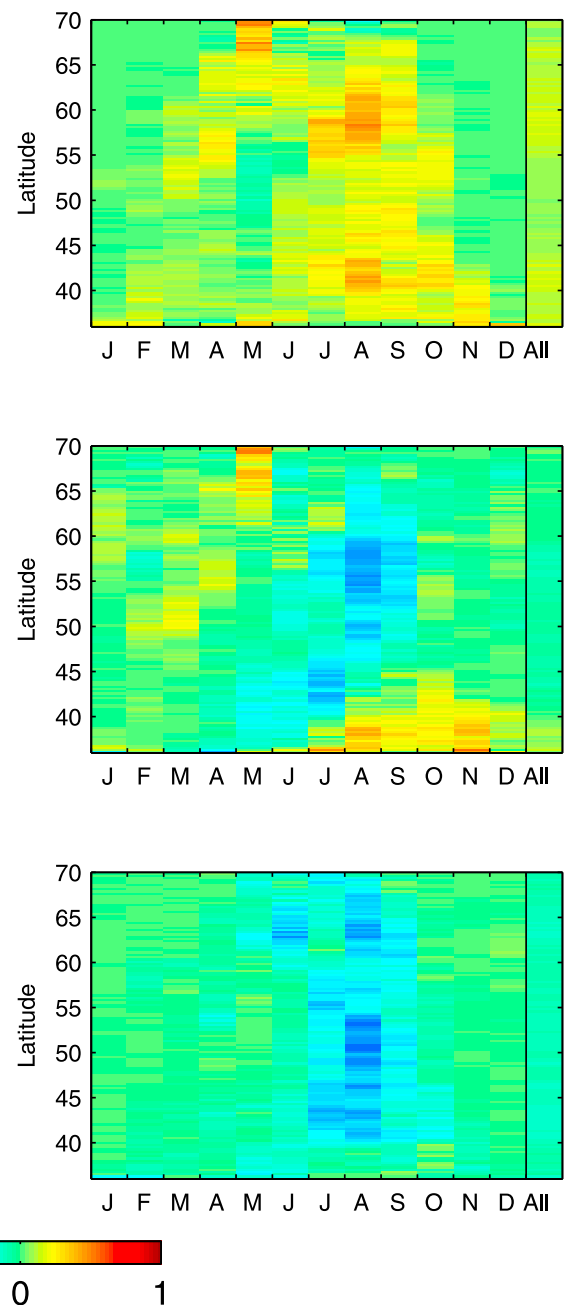

Figure 8. Mean lagged correlation between ORCHIDEE-modeled fluxes (GPP, TER, or NEE) for a given month and climate drivers (Ta or SWC) of the preceding month for a given latitude over Europe, weighted by 1 or 0 for critical and noncritical periods, respectively. Calculations utilize 14 years of simulations (1992-2005).

canopy photosynthesis and SWC in the model is due to the drought stress parameterization, which increases stomatal closure and decreases canopy photosynthesis when relative soil moisture drops below a fixed threshold [McMurtrie et al., 1990]. This SWC effect on canopy photosynthesis may be overestimated in Mediterranean regions (see Puechabon simulations in Figure 3), as further developed by Jung et al. [2007a]. The negative correlation between canopy photosynthesis and temperature variations during summer $\mathrm{CP}_{\mathrm{GPP}}$ in southern Europe and the negative correlation of canopy photosynthesis with SWC during summer in northern Europe was due to SWC-Ta covariation. Indeed, a partial correlation removing the effect of SWC on the GPP-Ta correlation had a lower correlation value for these regions and months (not shown). $\mathrm{CP}_{\mathrm{GPP}}$ could also be related to VPD and $\mathrm{Rg}$ anomalies but, as stated previously, we could not separate their direct effects and the effect of their covariance with Ta with a simple regression analysis.

[56] We also investigated the dependence of critical periods on climate anomalies from the preceding month
(Figure 8). A lagged effect of the temperature dependence of spring canopy development clearly appeared by $50^{\circ}-55^{\circ} \mathrm{N}$, and comparable direct (Figure 7) and 1 month lagged (Figure 8) correlations were observed between Ta and May GPP anomalies.

\subsubsection{TER}

[57] North of $50^{\circ} \mathrm{N}$, the TER anomalies were driven by temperature during $\mathrm{CP}_{\mathrm{TER}}$ from September to May. The positive correlation between TER and Ta during critical periods reflected the parameterization of soil organic carbon decomposition and of autotrophic maintenance respiration in ORCHIDEE. In the model, growth respiration also declined with canopy photosynthesis, which was positively correlated with Ta. Around $60^{\circ} \mathrm{N}$, from July to November, a positive correlation during critical periods appeared between TER and SWC as a consequence of the continental climate effect described above (Figure 6).

[58] In southern regions, the $\mathrm{CP}_{\mathrm{TER}}$ were sensitive to $\mathrm{SWC}$ during spring and summer (e.g., Mediterranean sites [Joffre et al., 2003; Pereira et al., 2007; Unger et al., 2009]). The 
existence of a latitudinal boundary between Ta and SWC controls, previously suggested by Reichstein et al. [2007b] in their site-specific analysis, was apparent in the model simulation, but was less clear for TER than for GPP. However, one can still distinguish in Figure 7 an approximate northern limit of $50^{\circ} \mathrm{N}$ for temperature-controlled TER annual anomalies.

[59] A striking result appeared from the lagged correlation analysis for TER (Figure 8). While direct correlations of SWC and TER summer anomalies illustrated that heterotrophic pool degradation was positively dependent on the activity of decomposers (Figure 7), lagged correlations indicated that TER anomalies in the current month were negatively dependent on previous month SWC anomalies. This relationship illustrated that the depletion of rapidly cycling organic matter pools under low moisture constraints (high SWC) decreased the respiratory flux of the current month.

\subsubsection{NEE}

[60] For most of the annual cycle and at any latitude, strong correlations between NEE and Ta or SWC were observed in fewer critical periods than correlations for elementary fluxes (Figure 7). The responses of gross fluxes to climate tended to compensate each other, causing only a weak spatial (crosssite) correlation between climate and NEE (Figure S1). A similar finding was described by Reichstein et al. [2007b], who showed on the basis of a few site years that the effects of Ta or SWC on the annual spatial variability of GPP and TER are of the same sign and similar magnitude.

[61] Some correlations occurred in northern Europe; NEE annual anomalies in these regions were negatively correlated to summer Ta (warmer conditions were associated with more net uptake) and positively correlated to summer SWC (wetter conditions were associated with less net uptake). A strong, negative correlation was also noted with Rg (Figures S1 and S2); because the effect of Ta on canopy photosynthesis was partly compensated by its effect on ecosystem respiration in summer, the Rg effect (via canopy photosynthesis) became more important. In our model-based results, the effect of Ta on spring $\mathrm{CP}_{\mathrm{NEE}}$ was low due to the compensating effects described above (Figure 7). However, several field studies showed that spring temperatures can influence annual NEE in boreal forests [Barr et al., 2004; Black et al., 2000; Chen et al., 1999; Goulden et al., 1998; Kljun et al., 2006; Suni et al., 2003a]. It is possible that the representation of phenology in ORCHIDEE, which seems to show some deficiencies (section 3.1 and Figure 4), cannot account for the fact that the direct effect of temperature on canopy photosynthesis is higher than its effect on ecosystem respiration over this period. Over southern Europe, flux anomalies in $\mathrm{CP}_{\mathrm{NEE}}$ were positively correlated to Ta anomalies in July and October (warmer, less uptake) and negatively correlated to SWC (drier, less uptake).

[62] GPP variability explained most of the NEE variability in European forests, as confirmed by other studies (Luyssaert et al. [2007] for three pine forests, and Reichstein et al. [2007b] for spatial NEE gradients across Europe). Indeed, in Figure 7, the NEE response to climate was broadly opposite to the response of GPP, with weaker correlations. This is also the case for the lagged correlations (Figure 8). Differences between the temporal location of critical periods for NEE and GPP appeared in winter, when the NEE variability reflects TER. However, in the model simulations, many
$\mathrm{CP}_{\mathrm{NEE}}$ were not directly controlled by a single climate variable but likely resulted from a more complex combination of direct and lagged climate conditions (Figures 7 and 8 at the European scale). This is especially likely to happen in temperate central Europe, close to the transition between northern, Ta-limited forests and southern, SWC-limited forests.

\section{Conclusions}

[63] This study provides insights into the temporal and climatic determinants of interannual flux variability. The ORCHIDEE model used for this study proved able to reproduce the general features observed at the site scale, although the model can still be improved to account for phenology and TER seasonal variability. It was shown that the interannual variability of carbon fluxes is often due to seasonal variability at one or several well defined periods of the year, which we called temporal "critical periods" of variability. However, at particular sites and regions, no critical periods could be detected for interannual flux variability, suggesting that the driving period for annual flux changes from year to year. In a second stage of analysis, it was shown that the variability in critical periods could be explained for some regions by the correlation of a flux anomaly with an anomaly in a single climatic factor. A boundary at roughly $55^{\circ} \mathrm{N}$ divides the positive correlations with soil water content and negative correlations with temperature observed in northern Europe from the opposite correlations in southern Europe. The spatial NEE anomaly pattern mainly followed that of GPP but was dampened by the compensating effects of TER. The latitudinal limit separating the predominant influences of soil water content and temperature on $\mathrm{CP}_{\mathrm{GPP}}$ (and thus $\mathrm{CP}_{\mathrm{NEE}}$ ) was shown to fluctuate along the annual cycle. Future changes in climate could modify the critical period patterns and, in particular, weather extremes within critical periods of the seasonal cycle could have an unexpectedly strong impact on annual carbon fluxes. Our investigations illustrate that studies of climate variability rather than average climate will reveal a more realistic picture of biosphere-atmosphere interactions, future carbon sequestration capacities and the vulnerability of land carbon pools to climate change.

[64] Acknowledgments. We are especially grateful to the investigators and teams managing the Hainich, Tharandt, Hyytiälä, Sorø, Loobos, Hesse, and Puéchabon eddy-flux sites. This study was conducted within the framework of the CARBOEUROPE-Integrated Project "Assessment of the European Carbon Balance" (GOCE-CT-2003-505572). Guerric le Maire was supported by a Region Ile-de-France postdoctoral fellowship through the "Réseau Régional de Développement Soutenable" (R2DS). We also thank the reviewers and editors for their valuable comments.

\section{References}

Allard, V., J. M. Ourcival, S. Rambal, R. Joffre, and A. Rocheteau (2008), Seasonal and annual variation of carbon exchange in an evergreen Mediterranean forest in southern France, Global Change Biol., 14(4), 714-725.

Amiro, B. D., et al. (2006), Carbon, energy and water fluxes at mature and disturbed forest sites, Saskatchewan, Canada, Agric. For. Meteorol., 136(3-4), 237-251.

Aubinet, M., et al. (2000), Estimates of the annual net carbon and water exchange of forests: The EUROFLUX methodology, Adv. Ecol. Res, 30, $113-175$.

Aubinet, M., B. Heinesch, and B. Longdoz (2002), Estimation of the carbon sequestration by a heterogeneous forest: Night flux corrections, 
heterogeneity of the site and inter-annual variability, Global Change Biol., 8(11), 1053-1071.

Ball, J. T., I. E. Woodrow, and J. A. Berry (1987), A model predicting stomatal conductance and its contribution to the control of photosynthetis under different environmental conditions, in Progress in Photosynthesis Research, edited by J. Biggens, pp. 221-224, Martinus Nijhoff, Dordrecht, Netherlands.

Barford, C. C., S. C. Wofsy, M. L. Goulden, J. W. Munger, E. H. Pyle, S. P. Urbanski, L. Hutyra, S. R. Saleska, D. Fitzjarrald, and K. Moore (2001), Factors controlling long- and short-term sequestration of atmospheric $\mathrm{CO}_{2}$ in a mid-latitude forest, Science, 294(5547), 1688-1691.

Barr, A. G., T. A. Black, E. H. Hogg, N. Kljun, K. Morgenstern, and Z. Nesic (2004), Inter-annual variability in the leaf area index of a boreal aspen-hazelnut forest in relation to net ecosystem production, Agric. For. Meteorol., 126(3-4), 237-255.

Barr, A. G., T. A. Black, E. H. Hogg, T. J. Griffis, K. Morgenstern, N. Kljun, A. Theede, and Z. Nesic (2007), Climatic controls on the carbon and water balances of a boreal aspen forest, 1994-2003, Global Change Biol., 13(3), 561-576.

Black, T. A., W. J. Chen, A. G. Barr, M. A. Arain, Z. Chen, Z. Nesic, E. H. Hogg, H. H. Neumann, and P. C. Yang (2000), Increased carbon sequestration by a boreal deciduous forest in years with a warm spring, Geophys. Res. Lett., 27(9), 1271-1274.

Botta, A., N. Viovy, P. Ciais, P. Friedlingstein, and P. Monfray (2000), A global prognostic scheme of leaf onset using satellite data, Global Change Biol., 6(7), 709-725.

Bousquet, P., P. Peylin, P. Ciais, C. Le Quere, P. Friedlingstein, and P. P. Tans (2000), Regional changes in carbon dioxide fluxes of land and oceans since 1980, Science, 290(5495), 1342-1346.

Chen, B., T. Black, N. Coops, T. Hilker, J. Trofymow, and K. Morgenstern (2009a), Assessing tower flux footprint climatology and scaling between remotely sensed and eddy covariance measurements, Boundary Layer Meteorol., 130(2), 137-167.

Chen, B., T. A. Black, N. C. Coops, P. Krishnan, R. Jassal, B. C. Mmer, and Z. Nesic (2009b), Seasonal controls on interannual variability in carbon dioxide exchange of a near-end-of rotation Douglas-fir stand in the Pacific Northwest, 19972006, Global Change Biol., 15, 1962-1981.

Chen, W. J., et al. (1999), Effects of climatic variability on the annual carbon sequestration by a boreal aspen forest, Global Change Biol., 5(1), 41-53.

Chen, Y., G. Churkina, and M. Heimann (2007), A comparison of regional climate variables between various data sources, Tech. Rep. ISSN16157400 , p. 8, Max-Planck-Inst. für Biogeochem., Jena, Germany.

Ciais, P., et al. (2005), Europe-wide reduction in primary productivity caused by the heat and drought in 2003, Nature, 437(7058), 529-533.

Ciais, P., et al. (2008), Carbon accumulation in European forests, Nat. Geosci., 1(7), 425-429.

Cohen, J. (1960), A Coefficient of Agreement for Nominal Scales, Educ. Psychol. Meas., 20(1), 37-46.

Delpierre, N., et al. (2009), Exceptional Carbon uptake in European forests during the 2007 warm spring: A data/model analysis, Global Change Biol., 15, 1455-1474.

de Rosnay, P., and J. Polcher (1998), Modelling root water uptake in a complex land surface scheme coupled to a GCM, Hydrol. Earth Syst. Sci., 2(2-3), 239-255

Desai, A. R., et al. (2008), Cross-site evaluation of eddy covariance GPP and RE decomposition techniques, Agric. For. Meteorol., 148(6-7), $821-838$.

Dolman, A. J., E. J. Moors, and J. A. Elbers (2002), The carbon uptake of a mid latitude pine forest growing on sandy soil, Agric. For. Meteorol., 111(3), 157-170.

Ducoudre, N. I., K. Laval, and A. Perrier (1993), Sechiba, a new set of parameterizations of the hydrologic exchanges at the land atmosphere interface within the LMD atmospheric general circulation model, J. Clim., 6(2), 248-273.

Dunn, A. L., C. C. Barford, S. C. Wofsy, M. L. Goulden, and B. C. Daube (2007), A long-term record of carbon exchange in a boreal black spruce forest: Means, responses to interannual variability, and decadal trends, Global Change Biol., 13(3), 577-590.

Falge, E., D. Baldocchi, J. Tenhunen, M. Aubinet, P. Bakwin, P. Berbigier, C. Bernhofer, G. Burba, R. Clement, and K. J. Davis (2002), Seasonality of ecosystem respiration and gross primary production as derived from FLUXNET measurements, Agric. For. Meteorol., 113(1-4), 53-74.

Farquhar, G. D., S. von Caemmerer, and J. A. Berry (1980), A biochemical model of photosynthetic $\mathrm{CO} 2$ assimilation in leaves of $\mathrm{C} 3$ species, Planta, 149, 78-80.

Feigenwinter, C., et al. (2008), Comparison of horizontal and vertical advective $\mathrm{CO}_{2}$ fluxes at three forest sites, Agric. For. Meteorol., 148(1), $12-24$.
Friedlingstein, P., G. Joel, C. B. Field, and I. Y. Fung (1999), Toward an allocation scheme for global terrestrial carbon models, Global Change Biol., 5(7), 755-770.

Goulden, M. L., J. W. Munger, S. M. Fan, B. C. Daube, and S. C. Wofsy (1996), Exchange of carbon dioxide by a deciduous forest: Response to interannual climate variability, Science, 271(5255), 1576-1578.

Goulden, M. L., et al. (1998), Sensitivity of boreal forest carbon balance to soil thaw, Science, 279(5348), 214-217.

Granier, A., et al. (2000), The carbon balance of a young Beech forest, Funct. Ecol., 14(3), 312-325.

Granier, A., et al. (2007), Evidence for soil water control on carbon and water dynamics in European forests during the extremely dry year: 2003, Agric. For. Meteorol., 143(1-2), 123-145.

Granier, A., N. Bréda, B. Longdoz, P. Gross, and J. Ngao (2008), Ten years of fluxes and stand growth in a young beech forest at Hesse, northeastern France, Ann. For. Sci., 65(7), 704.

Grünwald, T. (2003), Langfristige Beobachtung von Kohlendioxidflüssen mittels Eddy-Kovarianz-Technik über einem Altfichtenbestand im Tharandter Wald, Tharandter Klimaprotokolle, 7, $146 \mathrm{pp}$.

Hollinger, D. Y., and A. D. Richardson (2005), Uncertainty in eddy covariance measurements and its application to physiological models, Tree Physiol., 25(7), 873-885.

Hollinger, D. Y., et al. (2004), Spatial and temporal variability in forestatmosphere $\mathrm{CO}_{2}$ exchange, Global Change Biol., 10(10), 1689-1706.

Ibrom, A., P. G. Jarvis, R. B. Clement, K. Morgenstern, A. Oltchev, B. Medlyn, Y. P. Wang, L. Wingate, J. Moncrieff, and G. Gravenhorst (2006), A comparative analysis of simulated and observed photosynthetic $\mathrm{CO}_{2}$ uptake in two coniferous forest canopies, Tree Physiol., 26(7), 845-864.

Jacob, D., and R. Podzun (1997), Sensitivity studies with the regional climate model REMO, Meteorol. Atmos. Phys., 63(1), 119-129.

Janssens, I. A., et al. (2003), Europe's terrestrial biosphere absorbs 7 to $12 \%$ of European anthropogenic $\mathrm{CO}_{2}$ emissions, Science, 300(5625), $1538-1542$

Joffre, R., J. M. Ourcival, S. Rambal, and A. Rocheteau (2003), The keyrole of topsoil moisture on $\mathrm{CO}_{2}$ efflux from a Mediterranean Quercus ilex forest, Ann. For. Sci., 60(6), 519-526.

Jung, M., G. Le Maire, S. Zaehle, S. Luyssaert, M. Vetter, G. Churkina, P. Ciais, N. Viovy, and M. Reichstein (2007a), Assessing the ability of three land ecosystem models to simulate gross carbon uptake of forests from boreal to Mediterranean climate in Europe, Biogeosciences, 4(4), 647-656.

Jung, M., et al. (2007b), Uncertainties of modeling gross primary productivity over Europe: A systematic study on the effects of using different drivers and terrestrial biosphere models, Global Biogeochem. Cycles, 21, GB4021, doi:10.1029/2006GB002915.

Kalnay, E., et al. (1996), The NCEP/NCAR 40-year reanalysis project, Bull. Am. Meteorol. Soc., 77(3), 437-471.

Keenan, T., R. García, A. D. Friend, S. Zaehle, C. Gracia, and S. Sabate (2009), Improved understanding of drought controls on seasonal variation in Mediterranean forest canopy $\mathrm{CO}_{2}$ and water fluxes through combined in situ measurements and ecosystem modelling, Biogeosciences Discuss., 6(1), 2285-2329.

Kirschbaum, M. U. F. (2000), Will changes in soil organic carbon act as a positive or negative feedback on global warming?, Biogeochemistry, $48(1), 21-51$.

Kljun, N., T. A. Black, T. J. Griffis, A. G. Barr, D. Gaumont-Guay, K. Morgenstern, J. H. McCaughey, and Z. Nesic (2006), Response of net ecosystem productivity of three boreal forest stands to drought, Ecosystems, 9(7), 1128-1144.

Knohl, A., E.-D. Schulze, O. Kolle, and N. Buchmann (2003), Large carbon uptake by an unmanaged 250-year-old deciduous forest in central Germany, Agric. For Meteorol., 118(3-4), 151-167.

Krinner, G., N. Viovy, N. de Noblet-Ducoudre, J. Ogee, J. Polcher, P. Friedlingstein, P. Ciais, S. Sitch, and I. C. Prentice (2005), A dynamic global vegetation model for studies of the coupled atmosphere-biosphere system, Global Biogeochem. Cycles, 19, GB1015, doi:10.1029/ 2003GB002199.

Kruijt, B., J. A. Elbers, C. von Randow, A. C. Araujo, P. J. Oliveira, A. Culf, A. O. Manzi, A. D. Nobre, P. Kabat, and E. J. Moors (2004), The robustness of eddy correlation fluxes for Amazon rain forest conditions, Ecol Appl., 14(4), S101-S113.

Kutsch, W. L., O. Kolle, C. Rebmann, A. Knohl, W. Ziegler, and E. D. Schulze (2008), Advection and resulting $\mathrm{CO}_{2}$ exchange uncertainty in a tall forest in central Germany, Ecol. Appl., 18(6), 1391-1405.

Luyssaert, S., et al. (2007), Photosynthesis drives anomalies in net carbon-exchange of pine forests at different latitudes, Global Change Biol., 13(10), 2110-2127. 
Ma, S. Y., D. D. Baldocchi, L. K. Xu, and T. Hehn (2007), Inter-annual variability in carbon dioxide exchange of an oak/grass savanna and open grassland in California, Agric. For. Meteorol., 147(3-4), 157-171.

Magnani, F., et al. (2007), The human footprint in the carbon cycle of temperate and boreal forests, Nature, 447(7146), 848-850.

Mäkelä, A., M. Pulkkinen, P. Kolari, F. Lagergren, P. Berbigier, A. Lindroth, D. Loustau, E. Nikinmaa, T. Vesala, and P. Hari (2008), Developing an empirical model of stand GPP with the LUE approach: Analysis of eddy covariance data at five contrasting conifer sites in Europe, Global Change Biol., 14(1), 92-108.

Masek, J. G., and G. J. Collatz (2006), Estimating forest carbon fluxes in a disturbed southeastern landscape: Integration of remote sensing, forest inventory, and biogeochemical modeling, J. Geophys. Res., 111, G01006, doi:10.1029/2005JG000062.

McMurtrie, R. E., D. A. Rook, and F. M. Kelliher (1990), Modeling the yield of Pinus radiata on a site limited by water and nitrogen, For. Ecol. Manage., 30(1-4), 381-413.

Moffat, A. M., et al. (2007), Comprehensive comparison of gap-filling techniques for eddy covariance net carbon fluxes, Agric. For. Meteorol., $147(3-4), 209-232$.

Mouillot, F., and C. B. Field (2005), Fire history and the global carbon budget: A 1 degrees x 1 degrees fire history reconstruction for the 20th century, Global Change Biol., 11(3), 398-420.

Nabuurs, G.-J., M.-J. Schelhaas, G. M. J. Mohren, and C. B. Field (2003), Temporal evolution of the European forest sector carbon sink from 1950 to 1999, Global Change Biol., 9(2), 152-160.

Nobrega, S., and P. Grogan (2007), Deeper snow enhances winter respiration from both plant-associated and bulk soil carbon pools in birch hummock tundra, Ecosystems, 10(3), 419-431.

Papale, D., et al. (2006), Towards a standardized processing of net ecosystem exchange measured with eddy covariance technique: Algorithms and uncertainty estimation, Biogeosciences, 3(4), 571-583.

Parton, W. J., J. W. B. Stewart, and C. V. Cole (1988), Dynamics of C, N, $\mathrm{P}$ and $\mathrm{S}$ in grassland soils-A model, Biogeochemistry, 5(1), 109-131.

Patra, P. K., et al. (2008), TransCom model simulations of hourly atmospheric $\mathrm{CO}_{2}$ : Analysis of synoptic-scale variations for the period 2002-2003, Global Biogeochem. Cycles, 22, GB4013, doi:10.1029/ 2007GB003081.

Pereira, J. S., et al. (2007), Net ecosystem carbon exchange in three contrasting Mediterranean ecosystems-The effect of drought, Biogeosciences, 4(5), 791-802.

Piao, S. L., et al. (2008), Net carbon dioxide losses of northern ecosystems in response to autumn warming, Nature, 451(7174), 49-52.

Pilegaard, K., P. Hummelshoj, N. O. Jensen, and Z. Chen (2001), Two years of continuous $\mathrm{CO}_{2}$ eddy-flux measurements over a Danish beech forest, Agric. For. Meteorol., 107(1), 29-41.

Rambal, S., J.-M. Ourcival, R. Joffre, F. Mouillot, Y. Nouvellon, M. Reichstein, and A. Rocheteau (2003), Drought controls over conductance and assimilation of a Mediterranean evergreen ecosystem: Scaling from leaf to canopy, Global Change Biol., 9(12), 1813-1824.

Rannik, Ü., et al. (2002), Fluxes of carbon dioxide and water vapour over Scots pine forest and clearing, Agric. For. Meteorol., 111(3), 187-202.

Reichstein, M., J. D. Tenhunen, O. Roupsard, J.-M. Ourcival, S. Rambal, F. Miglietta, A. Peressotti, M. Pecchiari, G. Tirone, and R. Valentini (2002), Severe drought effects on ecosystem $\mathrm{CO}_{2}$ and $\mathrm{H}_{2} \mathrm{O}$ fluxes at three Mediterranean evergreen sites: Revision of current hypotheses?, Global Change Biol., 8(10), 999-1017.

Reichstein, M., et al. (2005), On the separation of net ecosystem exchange into assimilation and ecosystem respiration: Review and improved algorithm, Global Change Biol., 11(9), 1424-1439.

Reichstein, M., et al. (2007a), Reduction of ecosystem productivity and respiration during the European summer 2003 climate anomaly: A joint flux tower, remote sensing and modelling analysis, Global Change Biol., 13(3), 634-651.

Reichstein, M., et al. (2007b), Determinants of terrestrial ecosystem carbon balance inferred from European eddy covariance flux sites, Geophys. Res. Lett., 34, L01402, doi:10.1029/2006GL027880.

Remmert, H. (1991), The mosaic-cycle concept of ecosystems-An overview, in The Mosaic-Cycle Concept of Ecosystems, edited by H. Remmert, pp. 1-21, Springer, Berlin.

Richardson, A. D., et al. (2008), Statistical properties of random $\mathrm{CO}_{2}$ flux measurement uncertainty inferred from model residuals, Agric. For. Meteorol., 148(1), 38-50.
Santaren, D., P. Peylin, N. Viovy, and P. Ciais (2007), Optimizing a process-based ecosystem model with eddy-covariance flux measurements: A pine forest in southern France, Global Biogeochem. Cycles, 21, GB2013, doi:10.1029/2006GB002834.

Sitch, S., et al. (2003), Evaluation of ecosystem dynamics, plant geography and terrestrial carbon cycling in the LPJ dynamic global vegetation model, Global Change Biol., 9(2), 161-185.

Suni, T., F. Berninger, T. Markkanen, P. Keronen, Ü. Rannik, and T. Vesala (2003a), Interannual variability and timing of growing-season $\mathrm{CO}_{2}$ exchange in a boreal forest, J. Geophys. Res., 108(D9), 4265 doi:10.1029/2002JD002381.

Suni, T., et al. (2003b), Air temperature triggers the recovery of evergreen boreal forest photosynthesis in spring, Global Change Biol., 9(10), 1410-1426.

Thonicke, K., S. Venevsky, S. Sitch, and W. Cramer (2001), The role of fire disturbance for global vegetation dynamics: Coupling fire into a Dynamic Global Vegetation Model, Global Ecol. Biogeogr., 10(6), 661-677.

Unger, S., C. Máguas, J. S. Pereira, L. M. Aires, T. S. David, and C. Werner (2009), Partitioning carbon fluxes in a Mediterranean oak forest to disentangle changes in ecosystem sink strength during drought, Agric. For. Meteorol., 149(6-7), 949-961.

van der Werf, G. R., J. T. Randerson, G. J. Collatz, and L. Giglio (2003), Carbon emissions from fires in tropical and subtropical ecosystems, Global Change Biol., 9(4), 547-562.

van der Werf, G. R., J. T. Randerson, L. Giglio, G. J. Collatz, P. S. Kasibhatla, and A. F. Arellano (2006), Interannual variability in global biomass burning emissions from 1997 to 2004, Atmos. Chem. Phys., 6, 3423-3441.

van Gorsel, E., et al. (2009), Estimating nocturnal ecosystem respiration from the vertical turbulent flux and change in storage of $\mathrm{CO}_{2}$, Agric. For. Meteorol., 149(11), 1919-1930.

Vesala, T., et al. (2005), Effect of thinning on surface fluxes in a boreal forest, Global Biogeochem. Cycles, 19, GB2001, doi:10.1029/2004GB002316.

Vetter, M., et al. (2008), Analyzing the causes and spatial pattern of the European 2003 carbon flux anomaly using seven models, Biogeosciences, 5(2), 561-583.

Vickers, D., C. Thomas, and B. E. Law (2009a), Random and systematic $\mathrm{CO}_{2}$ flux sampling errors for tower measurements over forests in the convective boundary layer, Agric. For. Meteorol., 149(1), 73-83.

Vickers, D., C. K. Thomas, J. G. Martin, and B. Law (2009b), Selfcorrelation between assimilation and respiration resulting from flux partitioning of eddy-covariance $\mathrm{CO}_{2}$ fluxes, Agric. For. Meteorol., 149, $1552-1555$.

Welp, L. R., J. T. Randerson, and H. P. Liu (2007), The sensitivity of carbon fluxes to spring warming and summer drought depends on plant functional type in boreal forest ecosystems, Agric. For. Meteorol., $147(3-4), 172-185$.

P. Ciais, G. le Maire, and N. Viovy, Laboratoire des Sciences de Climat et de l'Environnement, CEA CNRS UVSQ, Orme des Merisiers, F-91191 Gif-sur-Yvette, France. (guerric.le_maire@cirad.fr)

N. Delpierre, Laboratoire Ecologie, Systématique et Evolution, UMR 8079, Université Paris-Sud, CNRS, AgroParisTech, F-91405 Orsay, France.

A. Granier and B. Longdoz, UMR INRA-UHP Écologie et Écophysiologie Forestières, INRA Centre de Nancy, F-54280 Champenoux, France.

A. Ibrom and K. Pilegaard, Biosystems Department, Risø National Laboratory for Sustainable Energy, Technical University of Denmark, PO Box 49, DK-4000 Roskilde, Denmark.

M. Jung and M. Reichstein, Max-Planck-Institute for Biogeochemistry, Hans Knöll Str. 10, D-07745 Jena, Germany.

P. Kolari and T. Vesala, Department of Physics, University of Helsinki, PO Box 64, FIN-00014 Helsinki, Finland.

E. J. Moors, Earth System Science - Climate Change, Alterra Wageningen UR, NL-6700 HA Wageningen, Netherlands.

S. Rambal, UMR 5175, DREAM, CEFE, CNRS, 1919 route de Mende, F-34293 Montpellier CEDEX 5, France.

A. D. Richardson, Department of Organismic and Evolutionary Biology, Harvard University Herbaria, Harvard University, 22 Divinity Ave., Cambridge, MA 02138, USA. 